\title{
PARENTAL PERCEPTIONS ABOUT THE IMPORTANCE OF PLAY IN THE FIRST THREE YEARS
}

\author{
BY \\ SUZANNE KATE HOLLAND
}

\begin{abstract}
A thesis
submitted to the Victoria University of Wellington

in fulfilment of the requirements for the degree of

Master of Education
\end{abstract}

Victoria University of Wellington

(2012) 


\begin{abstract}
Play is a universal and innate disposition that is believed to be one of the most significant components to holistic wellbeing and development during the foundational years of childhood. Research and literature examining the topic of play in early childhood suggests that while unstructured and child directed play is valued, its existence is under threat. Instead, it is being replaced by structured, educational, and adult directed activities which aim to accelerate young children's learning. Due to these conflicting paradigms, and a lack of research exploring parental values in this area, this quantitative study examined parental perceptions towards structured and unstructured play for children under the age of three years.

In order to investigate this topic, 255 New Zealand parents, with children not in full-time childcare and under the age of three years, participated in an anonymous online survey. The survey was designed specifically for this study due to a lack of pre-existing measures. The main finding was that parental perception influenced the way in which infants and toddlers spent their time. The majority of parents perceived unstructured play to best support early development and, consequently, offered children a large amount of daily time to become involved in freely chosen unstructured play. The study also identified that: the more weekly activities a child engaged in, the higher structured play was valued by parents; older parents did not value structured play as highly as younger parents; parents with a tertiary level qualification valued unstructured play more than those parents with a school qualification or less; screen time was perceived to be more appropriate the older the child. These findings were discussed in relation to the implications they raise for the role of the parent, early childhood education, parent education, and child development and wellbeing.
\end{abstract}




\section{Acknowledgements}

The undertaking and completion of this thesis would not have been possible without the assistance of many people. First, I would like to acknowledge Playcentre New Zealand for supporting this research; especially the organisation's secretary Jane Percival for her assistance in obtaining research approval and organising distribution of the survey. My sincere thanks to all the parents who took the time to complete the survey and share their insights. Thank you also to the children who inspired their responses. I wish to acknowledge my supervisor Associate Professor Vanessa Green for sharing her expertise in the field of academic research. Also my gratitude goes to Dr. Dalice Sim for her statistical support, my colleague Loreto Mattioni for her willingness to share her knowledge, and Mabel Hamon for her proofreading expertise. Most importantly I would like to thank my family, especially my Mum Adèle, for the endless belief, encouragement, and love. 


\section{Table of Contents}

$\begin{array}{ll}\text { Abstract } & \text { i }\end{array}$

Acknowledgements $\quad$ ii

Table of Contents $\quad$ iii

$\begin{array}{ll}\text { List of Tables } & \text { v }\end{array}$

$\begin{array}{ll}\text { Chapter One: Introduction } & 1\end{array}$

Introduction $\quad 1$

Rationale for the study 3

Study aims and research questions $\quad 4$

Overview of the thesis 5

$\begin{array}{lr}\text { Chapter Two: Literature Review } & 8\end{array}$

$\begin{array}{ll}\text { Introduction } & 8\end{array}$

$\begin{array}{ll}\text { Play } & 8\end{array}$

$\begin{array}{ll}\text { Unstructured play } & 10\end{array}$

$\begin{array}{ll}\text { Structured play } & 14\end{array}$

$\begin{array}{ll}\text { Parental perceptions } & 18\end{array}$

Research questions $\quad 22$

$\begin{array}{ll}\text { Hypotheses } & 22\end{array}$

$\begin{array}{ll}\text { Summary } & 23\end{array}$

$\begin{array}{ll}\text { Chapter Three: Methodology } & 24\end{array}$

Design $\quad 24$

$\begin{array}{ll}\text { Participants } & 24\end{array}$

Measures $\quad 25$

$\begin{array}{ll}\text { Procedure } & 26\end{array}$

$\begin{array}{ll}\text { Ethical considerations } & 27\end{array}$

$\begin{array}{ll}\text { Chapter Four: Results } & 28\end{array}$

$\begin{array}{ll}\text { Data analysis process } & 28\end{array}$

$\begin{array}{ll}\text { Participant demographics } & 29\end{array}$

$\begin{array}{ll}\text { Child demographics } & 30\end{array}$

Weekly activities 31

Structured play, unstructured play, and screen time 32 
Parental perception 33

Exploratory factor analysis $\quad 34$

Play and screen time perception $\quad 38$

$\begin{array}{ll}\text { Qualitative data } & 45\end{array}$

$\begin{array}{ll}\text { Summary of findings } & 48\end{array}$

Chapter Five: Discussion $\quad 5$

$\begin{array}{ll}\text { Introduction } & 50\end{array}$

Research questions 1 and 2: The extent to which parents value structured and unstructured play $\quad 51$

Research question 3: The relationship between perceptions and time 53

Research question 4: The relationship between demographic factors and parental perception $\quad 55$

Methodological contributions to the field $\quad 57$

Limitations and future research $\quad 58$

Theoretical and applied implications $\quad 59$

$\begin{array}{ll}\text { Conclusion } & 64\end{array}$

$\begin{array}{ll}\text { References } & 65\end{array}$

$\begin{array}{ll}\text { Appendices } & \mathbf{7 2}\end{array}$

$\begin{array}{ll}\text { Appendix A: Play survey } & 72\end{array}$

$\begin{array}{ll}\text { Appendix B: Ethics committee letter } & 78\end{array}$ 


\section{List of Tables}

Table 1 Frequency and percentage of parent qualification and age 30

Table 2 Frequency and percentage of child age, family type, and gender 31

Table 3 Type and numbers of activities involved in per week 32

Table 4 Time involved in structured play, unstructured play, and screen time per 33 day

Table 5 Total scores on the Play Perception Scale 34

Table 6 Component matrix initial analysis for PCA with forced four factor solution of parental perception items 35

Table 7 Patterns and structure matrix for PCA of oblimin rotation of two factor $\begin{array}{ll}\text { solution of parental perception items } & 37\end{array}$

Table 8 Descriptive statistics for the EFA components 38

Table $9 \quad$ Structured play hours and structured play perception 39

Table 10 Unstructured play hours and unstructured play perception 40

Table 11 Screen time hours and screen time perception 41

Table 12 Number of weekly activities and play perception 42

Table 13 Parent age and play perception $\quad 42$

Table 14 Parent qualifications and play perception 43

Table 15 Child age and play perception 44

Table 16 Family type and play perception 45 


\section{CHAPTER ONE: INTRODUCTION}

\section{Introduction}

This thesis provides a quantitative analysis of parental perception about the value and importance of play in supporting the development of children under three years of age. Being allowed to engage in play is acknowledged by the United Nations Convention on the Rights of the Child as the right of every child throughout the world (Child Rights Information Network, 2012). There is a wide range of literature and research supporting the concept of play in promoting healthy development in young children (Almon, 2004; Brown, 2010; Gleave, 2009; Jenkinson, 2001; Rushton, Juola-Rushton, \& Larkin, 2010; White \& Rockel, 2008). This universal and innate disposition is believed to be one of the most significant components to holistic wellbeing and development, especially during the foundational years of early childhood (Brown, 2010; Elkind, 2007; Frost, Wortham, \& Reifel, 2008; Pearce, 1992). However, it is the type of play which is best suited to achieve these positive outcomes that has received much debate in recent years. Specifically, current literature suggests that many more children in today's modern world are experiencing less time to engage in freely chosen play activities than they once did (Elkind, 2007; Gleave, 2009; Gray, 2011; Nicolopoulou, 2010). The first of the two types of play examined in this thesis is structured play which refers to experiences that are adult led with predetermined rules or outcomes and does not include routine times such as feeding or toileting. The second type of play is unstructured or free play which refers to experiences that are child led with no set rules or outcomes and does not involve screen time.

The focus of this thesis, in terms of these two contrasting types of play, is on children under the age of three years rather than preschool aged children between 3-6 years. There is a body of literature which examines school readiness and how experiences during early childhood, especially the preschool age, influence whether a child is prepared for the formal learning of a

primary school environment. Some of this research suggests that school readiness, which is considered a multidimensional concept including not only cognitive abilities but also behavioural and social development, is closely linked to parent and child relationships and parental involvement. For example, research suggests that children are more likely to succeed at school if their parent reads with them, engages in topical and meaningful discussions, encourages independence, and is emotionally nurturing and engaged (Edwards, Sheridan, \& Knoche, 2008; 
Maxwell \& Clifford, 2004; Parker, Boak, Griffin, Ripple, \& Peay, 1999; Webster-Stratton \& Reid, 2004). While this literature offers an interesting dimension to the role of the parent in preparing children for school, it will not be a main focus of this research as the literature around school readiness applies to preschool children aged 3-6 years. In contrast, this study focuses specifically on attitudes and perceptions of parents with infants and toddlers under the age of three years.

This younger age group was selected in order to examine parental perceptions not influenced by expectations of school readiness. As a result, it is hoped that findings will better reflect views about whether or not play is valuable, in and of itself, in fostering learning during the early years. The first three years of life are important to examine because during this period significant development takes place. Children's experiences during these early years determine how the brain is shaped and lay the foundation for future learning, happiness, and success (Fancourt, 2004). Frost et al. (2008) explain that play is an essential component to healthy brain development. Therefore, it is important to understand the play experiences in which infants and toddlers are involved, as a result of parental decision making, and to explore the influence these activities may have on their holistic development. This age group is also significant to consider as, even during these early years, there is a growing emphasis placed on structured learning and early academics (Elkind, 2007; Milteer \& Ginsburg, 2012; Nicolopoulou, 2010; Zigler \& Bishop-Josef, 2006).

The popularity of structured play activities has increased significantly in the past decade and there is a decrease in the amount of time young children engage in free, self initiated play (Almon, 2004). This shift has seen an increase in the number of educationally focused childcare settings as well as the development of structured activities and programmes aimed to promote early academic success in young children (Gleave, 2009; Nicolopoulou, 2010; Singer, Singer, D'Agostino, \& DeLong, 2009). For example, Baby Wow ${ }^{\mathrm{TM}}$, Baby Einstein ${ }^{\mathrm{TM}}$, and Your Baby Can $\operatorname{Read}^{\mathrm{TM}}$ are just a selection of the many programmes designed to teach infants and toddlers cognitive skills such as reading, counting, and recognising colours (Elkind, 2007). This focus towards educational and structured play during early childhood may be a result of parental pressure to ensure children reach their full potential. This pressure may also extend to early childhood educators feeling the need to prepare young children for the academic requirements of primary schools (Elkind, 2007; Milteer \& Ginsburg, 2012). 
There is also a growing body of literature examining the specific benefits of unstructured play in supporting the holistic and natural development of young children, especially during the first three years of life (Canning, 2007; Elkind, 2007; Pearce, 1992). For example, unstructured play, where children are provided with the opportunity to lead their own learning, has been linked with the development of neural connections in the brain, social skills such as perspective taking, language, physical skills, problem solving, and cognitive skills such as creative thought which can lead to later abstract thinking (Bergen, 2002; Frost, et al., 2008; Gimtrova \& Gimtrov, 2003; Hamilton \& McFarlane, 2005). It is argued that this form of play supports such development by enabling children to deepen their learning through following their individual interests and agendas and becoming fully engaged in the activity as they build on their current working theories about the world around them (Canning, 2007; Jenkinson, 2001).

These two paradoxical views on how to best support young children's learning and growth appear to be an area of contention amongst many early childhood professionals. Research examining the views held by teachers has found that the value placed on these two types of play in supporting early learning and development is wide ranging. The research shows that some educators advocate that unstructured play is most conducive to early learning and development while others argue that structured early experiences are most beneficial (Fisher, Hirsh-Pasek, Golinkoff, \& Gryfe, 2008; Ranz-Smith, 2007; Rothlein \& Brett, 1987). However, there is little research examining the views held by parents of infants and toddlers regarding structured and unstructured play. Given the significant influence that parents' beliefs and consequent choices have on children's early experiences, it would appear important to deepen understanding of the perspectives held by these individuals (Dancy, 2000). Therefore, this research aims to contribute to the field of early childhood by examining parental perceptions about the value of these two types of play and the influence these views have on the way children spend their time.

\section{Rationale for the study}

The focus of this thesis emerged through the examination of an eclectic range of educational approaches which inspired the research. Two of the key educational philosophies considered, which outline principles of caregiving, were developed by Hungarian paediatrician Emmi Pikler and Austrian philosopher Rudolf Steiner. The main aspects of these philosophies 
which have underpinned the development of this thesis enquiry are: engaging in respectful caregiving which recognises the competencies of the child; trusting and supporting the naturally unfolding development of the child; recognising the role of play in supporting this holistic growth; fostering secure attachment between child and key caregiver with an understanding that this is essential to the burgeoning of innate growth and learning (Klein, 2002; Raichle, 2008).

An additional educational framework that has contributed to the development of this research topic is the New Zealand Early Childhood Curriculum Te Whäriki. This document recognises the significant role that play has in supporting child development and acknowledges the holistic nature of children's learning which is shaped by all early experiences (New Zealand Ministry of Education, 1996). The role of the parent is also acknowledged in Te Whäriki which states that parents hold valuable insight into, and knowledge of, their children and that each child's family should be supported and respected so that the strong connections between all aspects of the child's world are promoted (New Zealand Ministry of Education, 1996). In accordance with this aspect of the curriculum, the thesis topic has been developed in order to explore the crucial role of the parent. This is especially relevant in modern times where there appears to be growing pressure on parents to ensure their children are cognitively prepared for the formal education environment in order to become successful and contributing members of society as adults. Literature suggests that this pressure is influencing the choices many parents make for their children and, as a result, play time for infants, toddlers and preschool children may be under threat (Elkind, 2007). As parents are arguably the most influential people in the life of a child, it appears necessary to deepen the knowledge of parental perception about play to understand how best to support parents in their role while simultaneously advocating for, and promoting, the wellbeing of the child.

\section{Study aims and research questions}

This study aims to make a theoretical contribution to the field of early childhood. It will provide insight into this study's under-researched focus area by examining parents' values and beliefs about structured and unstructured play in order to understand how these can influence a child's experiences during the foundational first three years of life. A new measure called the Play Perception Scale has been designed in order to investigate the four research questions and 
two research hypotheses in regards to parental perception about the importance of these two types of play.

In order to achieve the study's aims the following four research questions were developed. These are:

1. To what extent do parents value structured play in supporting learning and development in the first three years of childhood?

2. To what extent do parents value unstructured play in supporting learning and development in the first three years of childhood?

3. Do parental perceptions influence the way in which children spend their time?

4. Do demographic factors, such as parent age, parent education levels, child age, and family type, influence parental perception?

From these research questions and existing literature surrounding the topic two hypotheses were drawn. These are:

1. Parents who score highly on the Play Perception Scale regarding the importance of structured play in the first three years will prioritise structured time over unstructured time for their children.

2. Parents who score highly on the Play Perception Scale regarding the importance of unstructured play in the first three years will prioritise time for child initiated unstructured play and limit structured time.

\section{Overview of the thesis}

\section{Chapter one: Introduction}

This chapter provides an introduction to, and overview of, the thesis topic and provides the rationale for undertaking the study. It also outlines the research questions and hypotheses designed to achieve the delineated aims of the study.

\section{Chapter two: Literature review}

This chapter reviews the literature surrounding the topic of parental perceptions about the importance of play in order to position the research within a broader theoretical and empirical context and to identify the gaps requiring further examination and exploration. This chapter is organised into four main sections. The first discusses the definition and importance of play as well as examining its theoretical context. The second explores unstructured play including what 
it is, why it may be considered important in supporting the development of children under the age of three years, the role of toys in promoting unstructured play, the importance of outdoor play, and the theoretical context within which it sits. The third section discusses the concept of structured play by exploring what it is, the phenomenon of the hurried child, and how structured play relates to screen time. The final section explores parental perceptions including why the views of parents with infants and toddlers are important to consider within research and the wider context of early childhood as well as examining current research and understandings surrounding the topic. The study's research questions and hypotheses are also delineated along with a summary of the review.

\section{Chapter three: Methodology}

This chapter presents the methodological approach underpinning this quantitative survey research and clearly outlines the processes undertaken by the researcher in designing the study. It does this by outlining the chosen study design, the participants involved in the research, the utilised measures, the procedures, and the ethical considerations.

\section{Chapter four: Results}

This chapter discusses the results which were obtained from the anonymous online survey (see Appendix A). The data analysis process, which was undertaken on completion of data collection, is outlined in detail within this chapter. From here the results of the study are delineated in relation to: participant and child demographic findings; weekly activity findings; structured play, unstructured play and screen time findings; parental perception findings; research question findings; qualitative data findings. A scale called the Play Perception Scale was also developed as part of the online survey in order to assess parental perceptions about the value of play. An exploratory factor analysis (EFA) was run on this scale to test psychometric properties. This process is described in detail within this chapter. The main theme to emerge from participant responses to the survey was that parental perception influences the way in which children spend their time and that demographic characteristics, including parent age and educational levels as well as child age, influence these perceptions.

\section{Chapter five: Discussion}

This final chapter provides an in-depth discussion of findings in relation to the four research questions and the relevant literature surrounding these themes. Further, the methodological contributions to the field are outlined and limitations of the study are discussed 
alongside recommendations for future research. The theoretical and applied implications are also examined in relation to the role of the parent, early childhood education, parent education, and child development and wellbeing. The final section summarises the main findings to emerge from the study surrounding parental perception about the importance of play in supporting the holistic development of children under the age of three years. 


\section{CHAPTER TWO: LITERATURE REVIEW}

\section{Introduction}

The purpose of this research is to examine parental perception about the importance of play in the first three years. There is a wide range of literature supporting the crucial role of play in fostering children's natural holistic development during early childhood; a time when significant foundational learning takes place (Almon, 2004; Brown, 2010; Gimtrova \& Gimtrov, 2003; Jenkinson, 2001; Rushton, et al., 2010; White \& Rockel, 2008). However, literature also suggests that modern children are experiencing an upbringing that has greater structure and adult intervention than previous generations and that the value of free, unstructured, and child directed play is under threat (Elkind, 2007; Gleave, 2009; Gray, 2011; Hewes, 2006; Nicolopoulou, 2010; Spodek \& Saracho, 2003). Research examining parental perception about the value of play in supporting learning and development during the early years of life is limited and often this topic is examined in relation to teacher and student teacher attitudes and beliefs (Izumi-Taylor, Samuelsson, \& Rogers, 2010; Rothlein \& Brett, 1987; Sandberg \& Samuelsson, 2005). This research aims to offer a valuable, unique, and important contribution to the field of early childhood by addressing this deficit in understanding of parental attitude.

\section{Play}

\section{Definition and importance of play}

Play is an inborn disposition which enables children to learn, imagine, and explore their innate curiosity about the world around them (Elkind, 2007). According to Zeece and Graul (1990), the multidimensional construct of play can be defined by six key elements. These are: play as an intrinsically motivated activity; involving attention to the means rather than the end; being dominated by the child; relating to instrumental or pretence behaviour; not being bound by formal rules; requiring active participation from the child. The authors go on to outline three different forms of play that are: functional play which involves the use of the physical body to explore the surrounding environment; constructive play where children create using manipulative objects; dramatic play where children engage in make believe or pretence behaviours (Zeece \& Graul, 1990). 
According to Brown (2010), true play is a central component in enabling healthy and holistic development in children and its importance to life can be equated to the basic needs of sleep, food, water, and warmth. Like other animals, humans are believed to be biologically designed to play. As a result, this activity is paramount to a healthy childhood and, consequently, is experienced universally amongst all cultures in the world (Almon, 2004; Frost, et al., 2008; Pearce, 1992). Play has been recognised as being the crucial way in which children learn and develop their ability to engage in later higher order critical thought (Elkind, 2007; Pearce, 1992). For example, when children have opportunities to engage in creative thinking through play they are laying the foundational development required to enable abstract thinking in adult life (Bergen, 2002; Frost, et al., 2008).

Despite the social, political, and economic climate and contexts influencing child rearing and educational practices, play has historically been recognised as a legitimate and important trait of early childhood throughout the world (May, 2004). For example, at the turn of the twentieth century, John Dewey advocated for the emergence of free play in kindergartens in the United States (U.S.) due to his belief that children learn through active exploration and imitation (as cited in May, 2001). In the New Zealand context more play based philosophies began to emerge in kindergartens and nurseries by the 1940s due to the growing understanding about the power of play to elicit learning (May, 2001). In today's context research has shown that play is considered a vital component of early learning and development due to its place within many early childhood education curricula throughout the world (Bertram \& Pascal, 2002). As can be seen, play has been viewed for many years as a crucial element of childhood and a key way in which young children naturally learn, explore, discover, and develop. This concept has been recognised and formalised in Article 31 of the United Nations Convention on the Rights of the Child which states that children have the right to engage in play activities that are appropriate to their age (Child Rights Information Network, 2012). Lester and Russell (2010) argue that this right is as integral to upholding the worth of the child as the right to life, privacy, freedom of expression, and safety from abuse or neglect. As a result, the right to play should not be viewed as an extra component to be met only after the other rights have been set in place. The inclusion of this right is, in itself, recognition of the crucial role play has in the life of every child and it may therefore be assumed that a lack of opportunity to freely play is detrimental to a child's wellbeing. 
Research suggests a strong correlation between play and brain development in children because the brain does not work in isolation. Rather, it is linked to the rest of the body and is stimulated as a consequence of the thinking, feeling, and doing that is elicited through play (Almon, 2004). Play specifically supports healthy brain development through the programming of neural structures and by enabling the formation of neural connections. This hardwiring occurs at an especially fast rate during the first three years of life (Frost, et al., 2008). Current research suggests that early experiences greatly influence the way the brain develops. For example, it has been found that "critical aspects of brain architecture begin to be shaped by experience before and soon after birth, and many fundamental aspects of that architecture are established well before a child enters school" (Shonkoff, 2007, p. 1). A significant $85 \%$ of the brain is believed to be fully developed by the time a child reaches the age of three years and, as a result, children's experiences during these initial years lay the foundation for future learning, happiness, and success (Fancourt, 2004; Perry \& Szalavitz, 2006). This indicates that the way a child's brain grows, and the early childhood experiences that shape this development, is greatly influential to later holistic wellbeing (Brownlee, 2008; Frost, et al., 2008). Therefore, it appears important for parents, educators, and policy makers to understand how to best support such brain development through positive play based experiences.

There are a number of educational theorists who have advocated for the importance of play in supporting healthy development. Jean Piaget and Lev Vygotsky both stressed the essential role of play in promoting cognitive development. Piaget argued that children actively acquire knowledge through exploring or playing in the environment. Vygotsky stated that play is the source of learning, enabling interaction with others and providing the zone of proximal development in which children learn (as cited in Zigler \& Bishop-Josef, 2006).

\section{Unstructured play}

\section{Definition and importance of unstructured play}

The key element of unstructured play, also known as free play, is that it must be child directed and initiated instead of being structured and led by an adult (Canning, 2007; Elkind, 2007). With this in mind, unstructured play requires children to be given plenty of uninterrupted time for rich exploration in order to become truly involved in their internally motivated experiences (Gerber, 2002). Ruebke (2009) adds to this by stating that unstructured play must 
involve four elements in order to be truly effective. These are: freedom to explore and make independent choices; time to enter into the play process and unfold creativity; space in which to safely engage in play without the need for adult intervention; availability of a variety of objects that will support and foster imagination. It is the role of the adult to provide this rich play environment, as well as plenty of uninterrupted time, to allow the child to become fully involved in this meaningful and spontaneous free play (Hewes, 2006).

There is a wide range of literature supporting the crucial role of unstructured play in fostering children's holistic development during early childhood as foundational learning takes place. Oldfield (2001) highlights its importance in relation to children three years and younger, stating that infants and toddlers learn predominantly through the movement of their bodies. The author indicates that it is essential to offer children time and opportunity to engage in physical, child initiated play which enables them to explore the world around them in their own way and find their unique place within it. Canning (2007) argues that free play enables children to be active participants in the learning process as they engage in problem solving, creativity, and exploration of things which are meaningful and of interest to them as individuals. This can promote the development of internally motivated and self directed learners; two key dispositions which can support education in later life. Further, when children engage in these unstructured activities they are able to build working theories about the world around them by engaging in acts of imitation, problem solving, risk taking, trial and error, and exploration. This can also support the development of resilience, resourcefulness, social competence, and empathy which are arguably essential traits to possess in order to live a productive and meaningful life (Hamilton \& McFarlane, 2005; Jenkinson, 2001).

Unstructured play, especially pretend imaginary play, has been specifically linked to cognitive development in young children including perspective taking and abstract thought (Bergen, 2002; Gimtrova \& Gimtrov, 2003). A study conducted in the Slovak Republic examined the influence of teacher directed and child directed play on the cognitive competence of kindergarten children. Findings indicated that unstructured play initiated by the child was more conducive to the development of cognition than structured play. In this study, 51 children were observed as they engaged in the two different types of play and this was assessed in relation to predetermined cognitive behaviours (Gimtrova \& Gimtrov, 2003). Further, a longitudinal research study that was conducted across 12 childcare settings in England examined effective 
pedagogy in the early years. Findings from this research suggested that the best childcare environments were ones which ensured children had access to freely chosen play for at least half of their time in the setting (Siraj-Blatchford, Sylva, Muttock, Gilden, \& Bell, 2002).

One of the first theorists to support unstructured play and natural development was Jean Jacques Rousseau who believed that education should come from the liberal notion that humans are naturally free and good. He stated that children's work is to learn the limits and possibilities of their actions through freedom which, in turn, creates independence and happiness (as cited in May, 2004). Rousseau believed that through play children create the foundations of knowledge when left to engage with the natural world (as cited in Farne, 2005). As previously mentioned, U.S. philosopher, psychologist, and educational reformer John Dewey also advocated for the importance of unstructured play in supporting learning and development. This theorist argued that children should be given freedom to explore their surroundings and interact with others. $\mathrm{He}$ believed that such autonomy would allow each individual child to follow their unique interests, express themselves, and engage in meaningful learning (as cited in May, 2004). Despite the many benefits of unstructured play identified by theorists, educators, and researchers, there is growing literature that argues that young children today are given less time to freely and

naturally develop and that structured play based learning is gaining in popularity (Elkind, 2007; Hewes, 2006; Zigler \& Bishop-Josef, 2006).

\section{The role of toys in promoting or limiting unstructured play}

Play involving the use of toys can support the development of the imagination, which is an important disposition as creative thought acts as the foundation for later abstract thinking (Bradley, 1985; Elkind, 2007). Vygotsky believed that fantasy play was a leading factor in child development and explained that when children engage in make believe play they are able to explore, and build working theories around, complex thoughts and ideas (as cited in Berk, 1994). The structure of toys and resources can influence children's creative play by either limiting or expanding children's imaginations. Resources which are open ended in nature, with a number of different uses, are believed to best promote such imaginative play (Oldfield, 2001; Pulanski, 1970; Rubin, 1985). According to Klein (2002), this is because the more passive a toy, the more a child can exercise their imagination over the way it will be used. For example, a block can be used for building but can also be used as a car or a telephone; it has multiple uses and is only 
limited by the child's imagination and creativity. In contrast, when a toy only has one specific way of being used, creative thought is not required.

Research examining the effects of differently structured play materials on two groups of children found that the children who used open ended toys with a number of different uses displayed greater creativity compared with children who were given closed ended resources with specific and limited uses (Hirsh-Pasek \& Glolinkoff, 2003). A further study looking at play resources and materials identified that the most highly favoured toys amongst teachers, parents, and children themselves related to imaginary and dramatic play objects such as dress ups and tea sets (Rothlein \& Brett, 1987). However, it is noted that this research was conducted over 20 years ago and, as a result, may not reflect current perceptions. According to Elkind (2007), toys have become highly structured and more commercialised in recent years. The production of specialised play materials that are complicated and technologically advanced have grown significantly (Hughes, 2003). It would appear that the aims of creating such toys vary widely from being entertaining and promoting early education to encouraging mass toy consumption due to the singular use of many toys (Elkind, 2007; Hughes, 2003). Due to the often active nature of these structured toys, children's spontaneous play is not promoted and their internal motivation for learning is not fostered. It has been argued that when toys are passive and open ended children are empowered to be active participants using their intrinsic and innate impulse to freely and creatively drive their own learning (Canning, 2007; Gerber, 2002).

\section{Outdoor play}

Research examining children's outdoor play experiences in one childcare setting in New Zealand found that the outdoor environment enabled children to explore complex and unique play relating to physical challenges, dramatic play, constructive play, social play, and the exploration of the natural world (Stephenson, 1999). The opportunities for physical activity offered from unstructured outdoor play can also promote healthy development in children and lower the risk of later health problems, especially that of obesity (Burdette \& Whitaker, 2005; Milteer \& Ginsburg, 2012). Frost (2009) explains that the risks of limiting children's opportunities to engage in free outdoor play include a lack of creative ability, mental and physical health problems, including stress and obesity, as well as a low appreciation for nature. According to Tandon, Zhou and Christakis (2012), the responsibility to ensure children are given these crucial outdoor learning opportunities is largely placed on parents themselves who spend 
the majority of time with their children and, as a result, can have the most influence over the types of experiences children are offered during the early years of childhood.

U.S. research surveying mothers regarding outdoor play found that $85 \%$ of participants believed their children played outside less than they did as children (Gray, 2011). Further, research examining parent supervised outdoor play for U.S. preschoolers found that approximately half of the 9000 children involved in the study did not experience one play opportunity of this sort during an average day (Tandon, et al., 2012). This research is in line with the beliefs held by a number of authors who write that children today are spending much less time outside in the natural world. This is believed to be due to a number of factors including the indoor lifestyle of many adults, an increase in time children are involved in structured activities and screen time as well as parents' fears around outdoor safety (Frost, 2009; Gleave, 2009; Louv, 2005; Rivkin, 1995).

\section{Structured play}

\section{Definition and importance of structured play}

The key element which sets structured play apart from unstructured play is that it involves adult involvement and often has predetermined rules or outcomes set in place. For example, within this type of play the caregiver decides upon an activity in which the child is to be involved and then facilitates and directs the play experience (Gimtrova \& Gimtrov, 2003; Murata \& Maeda, 2002). This form of play, which reflects the traditional role of a teacher in the primary educational sector as the facilitator of learning, is becoming more common within early childhood (Almon, 2004; Elkind, 2007; Gimtrova \& Gimtrov, 2003). One possible reason for this growing popularity is that structured play is believed to be an effective way to encourage the development of specific skills, knowledge, and abilities (Gleave, 2009). While adult participation is the main trait of this play type, the way in which an adult is involved can vary greatly. Bredekamp and Rosegrant (1992) discuss the teaching continuum which ranges from nondirective teaching techniques, such as acknowledging children's play and modelling appropriate behaviours, to directive teaching techniques, such as demonstrating and directing play activities and behaviours. Mediating techniques, which include supporting children's play when necessary, sit in the middle of this continuum. The authors argue that different situations require teachers to adopt different techniques to most appropriately support children's play and 
their consequent learning (Bredekamp \& Rosegrant, 1992). Hewes (2006) suggests that the role of the adult is a critical component in children's play and that caregivers must be knowledgeable about the needs and interests of each child in order to make insightful judgements about how best to foster development and a sense of wellbeing through play. The author acknowledges the benefits of active adult involvement in structured experiences by stating that, when skilfully done, it can lead to more complex and sustained periods of play for children. This is because caregivers can enrich and extend these activities as well as offer strategies to overcome challenges and problems which may arise (Hewes, 2006). This view of the importance of structured play appears to be gaining momentum and is highlighted by the growing popularity of formalised play based activities aimed to support early learning. Such a shift in the focus of childhood experiences has been identified in literature and research as creating the phenomenon known as the hurried child (Almon, 2004; Elkind, 2007; Gray, 2011; Nicolopoulou, 2010).

\section{The hurried child}

A number of educators and researchers have stated that modern children are experiencing an upbringing with greater structure and adult intervention and that the value of unstructured, free play is under threat (Elkind, 2007; Gleave, 2009; Gray, 2011; Hewes, 2006; Nicolopoulou, 2010; Spodek \& Saracho, 2003). According to research undertaken by Rosenfeld, children's unstructured play activities have decreased by a significant $50 \%$ in the past decade which suggests that structured play is more highly valued by society than it once was (as cited in Almon, 2004). Possible reasons for such a shift include the rise in popularity and availability of technology, including television and computer use, a greater emphasis on developing early academic and cognitive ability in young children, and more time spent in structured activities, including sport and educational programmes (Almon, 2004; Elkind, 2007; Gleave, 2009; Hewes, 2006; Nicolopoulou, 2010; Zigler \& Bishop-Josef, 2006). Elkind (2007) explains that one of the most plausible reasons for such a shift is due to parental pressure to ensure children are not left behind or missing out on opportunities to develop to their full potential. There is a growing body of literature discussing the role of early childhood education in supporting school readiness and research suggests that the role of the parent is a key factor in determining a child's success when they enter the formal learning environment of school (Edwards, et al., 2008; Pelletier \& Brent, 2002). This paradigm may contribute to the growing pressure on parents to accelerate children's learning through adopting more adult led and deliberate teaching techniques earlier in a child's 
life. There is further literature which suggests that the decrease in unstructured play may also be due to the shifting emphasis of mainstream education. For example, there appears to be a movement towards increased assessment and instructional teaching in primary schools with a greater focus on the early development of specific academic skills (Milteer \& Ginsburg, 2012; Zigler \& Bishop-Josef, 2006). With this comes greater pressure on those who care for young children to promote the development of children's cognitive ability rather than follow the traditional guiding pedagogical practice of early childhood education which was strongly based on the role of play in promoting holistic development (Fleer, 2011).

Despite the intentions of caregivers to ensure children are given the best start, it has been argued that when children's development is rushed in such ways as mentioned above, the true nature of how young children learn is not recognised (Dancy, 2000; Elkind, 2007; Milteer \& Ginsburg, 2012). As a result, the question arises as to whether accelerating children's cognitive learning through structured and educational activities deprives the development of the whole child and internally driven learners who can independently and confidently explore and make sense of the world around them. Zigler and Bishop-Josef (2006) argue that education should adopt a whole child approach which recognises the holistic dimensions of development as opposed to focusing specifically on academic and cognitive performance. Research examining different preschool models in relation to later academic ability was conducted in the U.S. and included the assessment of over 300 children (Marcon, 2002). The study found that children who had early unstructured and child directed play experiences had greater later school success compared with children who attended academically focused preschools. A possible rationale for these findings was that the more structured models of early childhood education were believed to introduce formal learning too early and were not conducive to meeting the developmental needs of these young children (Marcon, 2002). Further research has identified negative effects of focusing on early academics and over structuring young children's time, including a link between the historical decline of free play and the rise in anxiety, depression, and feelings of helplessness (Gray, 2011). Katz (2008) discusses the mismatch between the popularity of promoting early academics and the current research examining early neural development and how brain function is best promoted through the meaningful and natural context of play. 


\section{Screen time}

Technological advancements are believed to have dramatically affected the way in which young children spend their time. Over the past decade there has been a significant rise in technology which is marketed directly to young children and their parents (Elkind, 2007). A study examining the amount of screen time infants and toddlers engage in suggests that children of this age group are exposed to large amounts of time involved in this activity and that these hours increase as children become older. The research found that by 3 months of age approximately $40 \%$ of the 1000 children surveyed watched 1 hour or more of television per day and this number rose to $90 \%$ for children aged 2 years (Zimmermann, Christakis, \& Meltzoff, 2007). Reported rationales for such a rise include: the heavy viewing habits of parents themselves; the perception that screen time promotes early learning; the belief that screen time will entertain children and is a safe way to keep children occupied while parents do jobs (Jordon, Hersey, McDivitt, \& Heitzler, 2006; Zimmermann, et al., 2007).

Almon (2004) explains that this increase in screen time, including television, movies, video games, and computer use, is one of the main reasons why children's unstructured play time is diminishing. While the appropriateness of exposing infants and toddlers to such forms of technology has received much international debate, negative findings have emerged from research. Healy (1991) reported that television viewing can greatly impact children's growing brains and their abilities to learn. For example, screen time was found to encourage both mental and physical passivity and, as a result, children became less active and their ability to creatively think or problem solve was negatively affected. A longitudinal survey based study, which involved over 1000 child participants who were assessed at 1, 3, and 7 years, examined the hours of daily television viewing alongside child behaviour (Christakis, Zimmermann, DiGiuseppe, \& McCarty, 2004). Findings revealed a link between excessive exposure to screen time during early childhood and the development of attentional problems in middle childhood (Christakis, et al., 2004). A further study conducted in the U.S. utilised structural equation modelling to test the relationship between the television viewing and school achievement of over 100 children aged between 6 and 1three years. Findings indicated that children who watched more television had lower academic success at school due to less time involved in homework and an increase in impulsive behaviour (Shin, 2004). As a result of such findings, which suggest more negative than positive effects on young children, the American Academy of Paediatrics recommends to 
parents in a policy statement that it is best to avoid exposing children under the age of 2 years to television, DVDs, and computers. Other recommendations suggest that unstructured playing time is more valuable for the brain development of infants and toddlers than exposure to electronic media (American Academy of Pediatrics, 2011). In line with this suggestion, Oldfield (2001) explains that young children require real and concrete experiences which are sensory rich and meaningful in order to learn. For children under three years old, the need to explore freely through movement is especially important as they master physical skills and find their place in the world (Jenkinson, 2001).

\section{Parental perceptions}

\section{Why parental perceptions are important to consider}

It is important to consider caregivers' perceptions around issues relevant to caring for and educating children because parents are children's first teachers and consequently the beliefs and knowledge held by these individuals will greatly influence children's early experiences (Dancy, 2000; Roopnarine, Shin, Jung, \& Hossain, 2003). It is therefore necessary that society, including early childhood educators who work in partnership with caregivers, value and promote the role of the parent (Braun, 1992; Nutbrown, 1994). While parents have the right and responsibility to choose whatever they feel is best for their child, not all have the knowledge or education to make informed decisions about best practice (Braun, 1992; Dancy, 2000). According to Stipek, Milburn, Clements, and Daniels (1992), appropriate parent education is necessary in order to enable parents to make conscious and well informed decisions about how best to support the developing child. This form of parent education is important in promoting children's future wellbeing and success. A study examining the parent and child relationship and home environment in relation to school readiness, found that parental ability to understand and facilitate play opportunities predicted positive outcomes in the classroom including an increase in children's independence and creativity (Parker, et al., 1999).

According to the ecological systems theory developed by Urie Bronfenbrenner, child development is influenced by the contextual elements surrounding the child, especially the element of relationships with parents. He valued the family structure so highly that he acknowledged it as being the most powerful influence in enabling, or denying, the capacity of

each individual to function effectively within their surrounding environment (as cited in Smith, 
1998). These key relationships are believed to be especially vital in the first three years of life when crucial brain development takes place. Such development relies heavily on a child's sense of security and safety which comes from consistent, responsive, and nurturing caregiving (Atwool, 2002; Fancourt, 2004; Shonkoff, 2007). As a result, it appears that parental beliefs, values, and child rearing practices impact on children's experiences and consequent development. Therefore, the examination of this area is significant in deepening parental understanding and developing educational practice.

\section{Current research and understandings}

According to the most recent Childcare Survey conducted by Statistics New Zealand, $53.9 \%$ of preschool aged children attend formal early childhood education and care services (Statistics New Zealand, 2010). These children will spend part of their week cared for by early childhood educators. Many teachers believe that play positively influences cognitive, physical, social, and emotional development (Izumi-Taylor, et al., 2010; Rothlein \& Brett, 1987; Sandberg \& Samuelsson, 2005). These findings are reflected in a number of early childhood curricula around the world. For example, the New Zealand Early Childhood Curriculum Te Whariki states that children's play should be "valued as meaningful learning and the importance of spontaneous play is recognised" (New Zealand Ministry of Education, 1996, p. 84). A study examining the early childhood curricula in 20 countries, including Australia, England, Sweden, the U.S., and Japan, found that there was almost universal agreement that a play based pedagogy is best in promoting learning during this early period of education. Some countries, such as Sweden, take this a step further by actively discouraging formal and structured approaches to education during early childhood (Bertram \& Pascal, 2002) .

As can be seen from the above statistics, nearly half of infants, toddlers and preschool aged children are cared for in informal childcare arrangements such as by parents in the home environment. Within these settings, there is no curriculum or pedagogical framework to guide or support best practice of care. The limited available research on parents' child rearing practices suggests that parental perceptions around the importance of structured and unstructured play in supporting development vary considerably. It appears that there are a number of factors which influence such perceptions including the education level of parents, the importance they place on preparing children for school and the value they place on formal activities over child directed play (Jensen, 2002; Rothlein \& Brett, 1987; Stipek, et al., 1992). For example, a study 
examining parental beliefs about appropriate education for young children and how best they learn found that parents' beliefs varied in relation to the value of formally teaching children basic skills. This study, conducted in the U.S., surveyed 551 parents with children aged 4-5 years who attended some form of early childhood education setting (Stipek, et al., 1992). The parent survey comprised questions relating to parent aspirations for their child, beliefs about the value of formal teaching techniques with an emphasis on early academics, and the types of learning activities parents engaged in with their children. Findings showed that parents who were more highly educated, such as those holding a tertiary qualification, valued didactic methods less highly than parents with less formal qualifications. This study also found a correlation between parents' beliefs around how best children learn and the types of activities in which their children engage. For example, those parents who valued adult led teaching strategies practiced more formal parenting practices, such as using flashcards and workbooks, with their children than parents who valued less formal parenting techniques. The focus of this study was on parental beliefs around the value of formal and informal techniques to support the early learning of preschool aged children and, as a result, the value of play in promoting natural development was not examined. However, this study focused on children aged 4-5 years and consequently parental views may have been influenced by the pressure of preparing children for the formal environment of primary school (Stipek, et al., 1992). The current research aims to avoid this possible influence on perception by focusing on younger children aged 0-three years.

Other research examining parental perceptions about play found that parent participants viewed play as fun and amusing but did not believe children should spend all their time engaged in this activity (Rothlein \& Brett, 1987). This study was also survey based and utilised a sample size of 73 parents with children aged between 2-6 years. The questionnaire asked parents to define what they believed play to be as well as to explain what they did to promote play for their children. However, it did not examine the value of different types of play, such as structured and unstructured, and there was no reporting on demographic influences on participant responses such as parent age or education levels (Rothlein \& Brett, 1987). Further survey research conducted in the U.S., and involving 1130 participants, examined the value mothers of children under 5 years old placed on unstructured and structured play (Fisher, et al., 2008). The survey scale comprised a 26 item list used to investigate how mothers conceptualise play, how these beliefs relate to children's academic learning, and any relationship between parental perception 
and the types of activities in which children engage. This research found that formalised activities were believed to be more conducive to developing academic ability in children. It also identified a relationship between parental belief and the types of activities in which children engaged. For example, mothers who valued play as a meaningful way to support learning reported that their children spent more time involved in play behaviours and activities but this was not reported in terms of whether the play was structured or unstructured (Fisher, et al., 2008). While examination of play perception in relation to structured and unstructured play was discussed by Fisher et al. (2008), the scale used was not provided in the report and, therefore, could not be utilised for replication. Further, demographic variables that could have offered insight into possible influences on parental perception were not examined.

A cross-cultural study of parental attitudes towards children's play also found that parents prefer scheduled and goal oriented activities to unstructured play activities. This was not because child directed play was considered inappropriate, but because parents felt that scheduled activities better prepared children for the demands of adult life (Jensen, 2002). This study was conducted in five countries and involved approximately 3000 parents with children between 0-12 years. The study involved the use of 10 questions designed to examine parental values towards children's time for play (Jensen, 2002). These questions formed the basis for the development of the Play Perception Scale which is utilised in this current study to examine parental perceptions in relation to structured and unstructured play. One interview-based study undertaken by Haight, Parke, and Black (1997) examined the beliefs held by 29 mothers and 29 fathers in the U.S. about the value they placed on toddlers engaging in pretend play. It found that pretend play was valued as a significant way to promote learning, especially in regards to cognitive development. This is one of the few studies identified that specifically examined the play perceptions of parents with children under 36 months of age. The findings which promote play may therefore be a reflection on the specific and younger age group being examined compared with the previously discussed studies which included children up to the age of 5 years or older.

As can be seen, prior research has examined parental perception around the value of play in promoting child development. However, none of these studies have looked specifically at the value parents place on structured and unstructured play in relation to children under three years of age. While one study undertaken by Fisher et al. (2008) did address these two types of play, it involved parents with children up to the age of 5 years. As a result, the findings may have been 
influenced by possible expectations on parents to prepare children for the formal learning of school environment as previously discussed. It would appear that there is a gap in research looking at the types of play that younger children are involved in when parents are less focused on school readiness. Such an examination may deepen understanding about the value of play, in and of itself, from the perspective of the parent. Two studies by Fisher et al. (2008) and Stipek et al. (1992) provided evidence based support for the current study's two hypothesis. This is because both pieces of research identified a link between parental beliefs and attitudes about play with the type of play activities in which their children spent the most time. Only one of the relevant studies, also by Stipek et al. (1992), examined possible demographic influences on parental perception. However, this was only in relation to education levels of parents and did not address other demographic factors such parent age, child age, and family type. The present study aims to expand such demographic understanding and offer further insight into what may influence the beliefs held by parents of children under the age of three years.

\section{Research questions}

1. To what extent do parents value structured play in supporting learning and development in the first three years of childhood?

2. To what extent do parents value unstructured play in supporting learning and development in the first three years of childhood?

3. Do parental perceptions influence the way in which children spend their time?

4. Do demographic factors, such as parent age, parent qualification, child age, and family type, influence parental perception?

\section{Hypotheses}

1. Parents who score highly on the Play Perception Scale regarding the importance of structured play in the first three years will prioritise structured time over unstructured time for their children.

2. Parents who score highly on the Play Perception Scale regarding the importance of unstructured play in the first three years will prioritise time for child initiated unstructured play and limit structured time. 


\section{Summary}

According to the literature, play is a natural and universal element of early childhood and allowing time for free, child initiated play is important as it provides children with invaluable opportunities to: develop holistically and build crucial neural connections in the brain which act as the foundation for later learning and experience; meaningfully learn about the world around them and their place within it; become internally motivated, active, and confident explorers and learners. However, research suggests that the time modern children are spending involved in this form of play is diminishing significantly due to a number of factors including technological advancements, more time involved in structured activities, and a greater emphasis on early cognitive learning. Despite the great influence of parental practices on children's early experiences, current research surrounding parental perceptions of the value of structured and unstructured play during the first three years of childhood is limited. This study aims to offer a valuable, unique, and significant contribution to the field of early childhood. 


\section{CHAPTER THREE: METHODOLOGY}

\section{Design}

This study employed a non-experimental survey research design which is best suited to identify the characteristics of a population and examine the thoughts, attitudes, values, perceptions, and behaviours of participants (Johnson \& Christensen, 2008). To examine the research questions posed, a quantitative research study was conducted. A key objective of educational research is to explore and generate ideas about a specific phenomenon and quantitative research enables this to be achieved by obtaining numerical data on the subject (Johnson \& Christensen, 2008). An anonymous online survey, asking parents how children spend their time and their perceptions about the value of structured and unstructured play, was used as the data collection instrument (see Appendix A). Because the topic of this thesis is under-researched, this quantitative study design enabled parental perceptions about play to be examined in order to provide foundational knowledge on the subject. A final qualitative open ended statement was asked at the end of the survey in order to gain a deeper understanding of parental perceptions around the value of play to enable further exploration of the quantitative findings.

\section{Participants}

New Zealand parents with children not in full-time childcare and under the age of three years were invited to participate in the online survey. The rationale for focusing on parents who chose not to send their child to full-time early childhood education and care was to ensure parents were responsible for the way in which their child spent the majority of their time. As a result, respondents would be able to answer the survey questions around time more reliably and answers would more accurately reflect parental perception, rather than the educational philosophies underpinning a childcare setting. The parent group for this study was acquired through Playcentre New Zealand. This organisation was contacted and a research application was submitted. Once this application was approved, an introductory parent e-mail containing the URL link to the survey was sent to Playcentre which distributed it to their database of parents.

The approximate population size of children three years or younger in New Zealand is 190,000 (Statistics New Zealand, 2012). However, as the participants were drawn from a 
non-probabilistic convenience sample, a minimum parent sample size of at least one hundred participants was selected with the understanding of the risk of selection bias. To overcome some participant bias, the study utilised the organisation Playcentre that operates throughout New Zealand in order to survey participants from a range of settings, backgrounds, and ethnicities. However, it is acknowledged that parents who choose to attend this form of early childhood provision with their children may already hold insight into the value of play due to the philosophy of parental involvement and education which is the cornerstone of the organisation (Playcentre New Zealand, 2012b). Playcentre has approximately 11,000 families enrolled in their 33 Associations throughout the country (Playcentre New Zealand, 2012a). All Associations were sent the e-mail and the accompanying survey link and asked to distribute these to their database of parents.

\section{Measures}

An online parent survey was specifically designed for the purposes of this research. Due to the limited research in this area, no measures have been created to date to assess parental perceptions about structured and unstructured play specifically for children under the age of three years. As a result, no pre-existing survey could be used as a standard measure for this research. However, a study conducted by Jensen (2002) examined parental values and attitudes towards play for children up to the age of 12 years. This study contained 10 questions covering six themes. The themes focused on parental attitudes towards play, perceptions around what constitutes play, attitudes towards scheduled activities, balancing planned and freely chosen activities, time for free play, and the value of free play. This research provided the basis for the development of the current Play Perception Scale but, because of the large age range of children included in the Jensen (2002) study, not all questions used were appropriate for the current research. For this reason questions were adapted or replaced with more suitable ones. For example, while the themes were similar, all statements in this current study were re-worded from the Jensen (2002) study to relate more closely with the age group being examined and the specific topic of structured and unstructured play. The themes examined in the Play Perception Scale focused on discovering parental perceptions about the importance of unstructured, free play versus structured play in supporting the learning and development of infants and toddlers. Further, the Play Perception Scale included questions about toys, outdoor time, and screen time. 
This inclusion was based on the literature which acknowledges these topics as relevant areas of debate in relation to how young children spend their time and how they support or hinder structured and unstructured play opportunities and children's consequent learning and development.

The current study's survey contained a cover letter followed by three survey sections. The cover letter introduced the research, outlined how data was to be used, and contained details about ethics and confidentiality of the collected data. It also included a consent statement which delineated the fact that participation was voluntary and that respondents could choose to withdraw at any stage before the end of the survey when it was submitted. Instructions about how to complete the survey and who was eligible to complete it, specifically parents with children under the age of three years, were also included.

The first section of the survey gathered personal demographic information about the participants, including the gender, age, and education of the parent, with the use of multiple choice and written options. The second section focused on one of the participant's children under the age of three years who did not attend full-time childcare. It enquired about the gender and age of the child as well as how the child typically spent their time. This also used a combination of multiple choice and written answers. The last section utilised this survey's newly developed Play Perception Scale containing eight questions which related to parental perceptions about the importance of play in supporting development. These were rated on a 5point Likert scale which ranged from strongly disagree (1) to strongly agree (5). Half of these questions were reverse scored. A final qualitative question was included to provide respondents with the opportunity to state their views on the importance of structured and unstructured play.

\section{Procedure}

A pilot sample was selected to pre-test the online survey to ensure its suitability in terms of ease of use and time for completion. This sample was comprised of seven mothers and one father ranging in age from 25-40 years with varying levels of education from school qualification to postgraduate degree. Upon retrieval of feedback from the eight pre-test participants, additional changes were made to the survey in order to better reflect the research questions. An introductory e-mail containing the URL link to the survey was then sent to Playcentre New Zealand who had previously approved the research through their ethics committee and had 
confirmed their interest in supporting the study. This e-mail was initially sent to the Playcentre secretary who distributed it to the 33 Playcentre Associations throughout New Zealand which, in turn, forwarded the e-mail to their individual Centres. The e-mail was then sent by each Centre to their database of parents. Parents could then choose whether or not to partake. If they volunteered to participate, respondents followed the URL link to the survey website. Parents were initially asked to read and consent to the information stipulated in the cover letter before continuing with the survey. They could not commence the survey until they had ticked a consent box on the blocked cover letter page. On completion of the survey, results were stored in the private research software held by Victoria University of Wellington. The online survey was available to participants for one month before it was deactivated.

\section{Ethical considerations}

Johnson and Christensen (2008) recognise that the treatment of research participants is the most fundamental ethical issue for researchers to consider when conducting research with human involvement. In order to ensure ethical considerations were upheld within this research, and because this study involved human participants, an ethics application was submitted to the Victoria University Faculty of Education Ethics Committee before the commencement of data collection. This study was granted ethics approval by the Committee on 3 April 2012 (see Appendix B).

The participant parents were asked to read the covering letter and informed consent was obtained from all participants prior to commencing the survey. All data was collected anonymously and confidentially and participants were informed that they could withdraw from the study at any time before their responses were submitted. In addition, all data is securely and privately stored and will be retained for 5 years post completion of the study and only accessed by the researcher during this time. All participants were informed of the opportunity to obtain the final research report through the Faculty of Education, Victoria University of Wellington website. 


\section{CHAPTER FOUR: RESULTS}

\section{Data analysis process}

Participant survey responses were collected online using a software package called Qualtrics. A total of 255 responses were obtained. This data was subsequently downloaded into the Statistical Programme for Social Sciences (SPSS) Version 20 software before being sorted and cleaned. The survey responses of 21 participants, who did not answer key questions required to test the study hypotheses, were deleted. These included all surveys where less than $50 \%$ of questions were answered, all those that did not answer questions about structured play, unstructured play, screen time, and weekly activities (questions 8-11) and all those that did not answer the questions relating to participant perceptions (question 12). A total of 234 usable responses remained. Further cleaning of the data involved an examination of overall participant responses. Any multiple choice category which had been selected by less than 5 participants was re-grouped into an existing category for the purposes of analysis. This process did, however, exclude the number of hours engaged in structured and unstructured play in order to enable a thorough reflection of the spread of this data. Total activity scores for the number of activities engaged in by children were obtained by adding the total activities recorded in question 11 . Next, the four questions that were reverse scored in the eight item Play Perception Scale survey (i.e. questions $12 \mathrm{~b}, 12 \mathrm{c}, 12 \mathrm{f}$, and $12 \mathrm{~h}$ ) were re-coded to ensure consistency in coding and subsequent analysis. A total parental perception score was then obtained by adding the scores reported in the eight item Play Perception Scale for each participant. A low score was indicative of supporting structured play (minimum score of 8) and a high score indicative of supporting unstructured play (maximum score of 40).

Descriptive analyses examined demographic variables of the survey respondents and their focus child by obtaining frequencies and percentages for questions 1-7. These characteristics included the gender, age, ethnicity, and educational qualification level of parents as well as family type and the gender and age of the focus child. The second stage in the analysis process was to identify what the participants' responses were in relation to questions 8-11 of the survey. These questions examined the type and amount of activities children engaged in during an average week and how many hours in an average day parents estimated their child spent involved in structured play, unstructured play, and screen time. In order to examine these 
findings frequencies, percentages, means, and standard deviations were obtained. The same statistics were also obtained from the already summed total scores taken from the Play Perception Scale.

One of the research questions of this study was to examine if the differing perceptions held by parents influenced the way in which children spent their time. It was hypothesised that children would spend more time involved in self initiated play experiences if their parents valued unstructured play and, in contrast, that children would spend more time in structured, adult led activities if their parents valued this form of play more highly. Therefore, the final stage of analysis was to identify significant findings between the dependant variables of the Play Perception Scale and the independent variables of hours engaged in structured and unstructured play, hours involved in screen time, weekly activities, parent age, parent qualifications, child age, and family type. This was achieved by first conducting an EFA in order to identify the key components underlying the Play Perception Scale section of the survey (question 12). The responses which related to the two identified factors were then saved in the form of factor scores. From here mean-based analyses (t-tests and one-way analysis of variance) were run in order to identify relationships between the key perception factors and the independent variables.

Finally, qualitative data was analysed with the use of thematic analysis. Two independent raters, who were blind to the aims of the study, analysed the content of the comments section. The data was coded based on the identification of recurrent words, phrases, patterns, and themes (Morse \& Field, 1995). Inter-rater agreement was established by comparing the coding of data and creation of categories between raters. Agreement was high and analyses were refined until agreement was reached about all major coding categories. In total five key themes emerged.

\section{Participant demographics}

The vast majority $(97.9 \%, N=228)$ of the 234 surveyed participants were mothers and most of the respondents were aged between 30-39 years of age $(70.7 \%, N=164)$. Only $14.7 \%$ $(N=34)$ were aged 29 years and under with the same amount of participants aged 40 years or older $(14.7 \%, N=34)$. A high majority of respondents identified as New Zealand European $(78.6 \%, N=184)$ with the remainder identifying themselves as European $(14.1 \%, N=33)$, Maori $(2.1 \%, N=5)$ or fitting into the category of Other which included Asian and Pacific 
Island ethnicities $(5.1 \%, N=12)$. Just under half of the respondents stated that their highest qualification was a bachelor degree $(46.1 \%, N=107)$, with $50.4 \%(N=117)$ reporting that they held a school qualification, certificate, diploma or another type of qualification, and 3.45\% $\quad(N$ $=7$ ) having no formal qualification. As delineated in Table 1, the largest number of participants from all three age groups held a bachelor degree. Only 11.8\% $(N=4)$ of participants aged 29 years or younger held no formal qualification with even less for those aged between 30-39 years $(1.2 \%, N=2)$ and 40 years or older $(2.9 \%, N=1)$.

\section{Table 1}

Frequency and percentage of parent qualification and age

\begin{tabular}{|c|c|c|c|c|c|c|}
\hline \multirow[t]{3}{*}{ Qualification } & \multicolumn{6}{|c|}{ Parent age } \\
\hline & \multicolumn{2}{|c|}{29 yrs and under } & \multicolumn{2}{|c|}{$30-39$ yrs } & \multicolumn{2}{|c|}{40 yrs and over } \\
\hline & $N$ & $\%$ & $N$ & $\%$ & $N$ & $\%$ \\
\hline No Qualification & 4 & 11.8 & 2 & 1.2 & 1 & 2.9 \\
\hline School Qualification & 7 & 20.6 & 25 & 15.3 & 5 & 14.7 \\
\hline Certificate & 3 & 8.8 & 13 & 8.0 & 3 & 8.8 \\
\hline Diploma & 7 & 20.6 & 13 & 8.0 & 2 & 5.9 \\
\hline Bachelor Degree & 11 & 32.4 & 78 & 47.9 & 18 & 52.9 \\
\hline Other & 2 & 5.9 & 32 & 19.6 & 5 & 14.7 \\
\hline
\end{tabular}

\section{Child demographics}

Only 7.3\% $(N=17)$ of the participating population reported having 4 or more children, 21.5\% $(N=50)$ had 3 children, $48.5 \%(N=113)$ had 2 children, and 22.7\% $(N=53)$ had 1 child. Other demographic data showed that there was an exact split regarding the gender of the focus child, with $50 \%(N=116)$ being male and 50\% $(N=116)$ being female. It was reported that the largest group of children were aged between 25-30 months (30\%,N=70), a further $21.5 \%(N=50)$ of children were between 31-35 months, $23.2 \%(N=54)$ were between 19-24 months, $15.5 \%(N=36)$ were aged between $13-18$ months, and only $9.9 \%(N=23)$ were 12 months or younger. Frequency and percentage of children from the five age groups, in relation to their gender and whether they were from a one child family or had siblings, is presented in Table 2. As can be seen, the largest group of boys from a one child family were aged between $19-24$ months $(40 \%, N=8)$ and the same age group held the largest number for girls from one 
child families $(30.3 \%, N=10)$. However, for both genders the focus children aged between 2530 months were from the highest percentage of families comprising two or more children. For boys this was $32.3 \%(N=31)$ and for girls this was $33.3 \%(N=27)$.

\section{Table 2}

Frequency and percentage of child age, family type, and gender

\begin{tabular}{lccccccrr}
\hline $\begin{array}{l}\text { Child } \\
\text { age in } \\
\text { months }\end{array}$ & Only child & \multicolumn{2}{c}{ Male } & \multicolumn{3}{c}{ Female } \\
& $N$ & $\%$ & $N$ & $\%$ & $N$ & $\%$ & $N$ & $\%$ \\
\hline $0-12$ & 0 & .0 & 10 & 10.4 & 1 & 3.0 & 10 & 12.3 \\
$13-18$ & 7 & 35.0 & 14 & 14.6 & 9 & 27.3 & 5 & 6.2 \\
$19-24$ & 8 & 40.0 & 21 & 21.9 & 10 & 30.3 & 15 & 18.5 \\
$25-30$ & 4 & 20.0 & 31 & 32.3 & 8 & 24.2 & 27 & 33.3 \\
$31-35$ & 1 & 5.0 & 20 & 20.8 & 5 & 15.2 & 24 & 29.6 \\
\hline
\end{tabular}

\section{Weekly activities}

Table 3 shows that in relation to the type of activities children engaged in during an average week, 93.6\% $(N=219)$ attended Playcentre which is not surprising given that Playcentre parents formed the participant group for this survey. Music classes (30.8\%, $N=72)$, gym class $(10.3 \%, N=24)$, swimming lessons $(26.5 \%, N=62)$, part-time childcare $(22.2 \%, N=52)$, and playgroup $(20.5 \%, N=48)$ were also popular activities for children. The remaining activities were attended by $10.7 \%(N=25)$ of the participants' children. Further, findings showed that children, on average, engaged in $2.15(S D=1.10)$ activities a week with $1.7 \%(N=4)$ of children attending no activities. Of the focus children $63.7 \%(N=149)$ attended $1-2$ activities, $32.9 \%(N=77)$ attended 3-4 activities, and only $1.7 \%(N=4)$ of children attended 5 or more activities during an average week. 


\section{Table 3}

Type and number of activities involved in per week

\section{Focus children aged under three years}

\begin{tabular}{lrr} 
Activities & $N$ & $\%$ \\
\hline Type: & 72 & 30.8 \\
Music class & 24 & 10.3 \\
Gym class & 62 & 26.5 \\
Swimming lesson & 48 & 20.5 \\
Playgroup & 219 & 93.6 \\
Playcentre & 1 & .4 \\
Parent-child education & 52 & 22.2 \\
Part-time childcare & 24 & 10.3 \\
Other & 4 & 1.7 \\
None & & \\
Number: & & 1.7 \\
0 & 4 & 30.8 \\
1 & 72 & 32.9 \\
2 & 77 & 23.1 \\
3 & 54 & 9.8 \\
4 & 23 & 1.7 \\
$5+$ & 4 &
\end{tabular}

\section{Structured play, unstructured play, and screen time}

Table 4 shows children were involved in an average of $2.04(S D=1.04)$ hours of structured play per day. The majority of children engaged in 0-1 hour of structured play per day $(72.1 \%, N=168)$, while $21 \%(N=49)$ of children engaged in this form of play for 2 hours a day, and only $6.8 \%(N=16)$ of children were involved for 3 or more hours a day. In contrast, children were involved in a much higher average of $6.21(S D=1.15)$ hours of unstructured play per day. The majority of children reportedly engaged for 6 or more hours a day $(58.4 \%$, $N=136)$, with $30.5 \%(N=71)$ involved in unstructured play for 4-5 hours a day, and only $11.2 \%(N=26)$ engaged in $0-3$ hours. Children spent an average of $1.86(S D=0.87)$ hours 
engaged in screen time daily. A total of $41 \%(N=96)$ of children engaged in no screen time at all during an average day, with the second highest amount of 36.3\% $(N=85)$ engaging in 1 hour a day, $17.9 \%(N=42)$ engaging in 2 hours a day, and only $4.6 \%(N=11)$ engaging in 3 or more hours of daily screen time.

\section{Table 4}

Time involved in structured play, unstructured play, and screen time per day

\begin{tabular}{lrrrrrr}
\hline Hours & Structured play & \multicolumn{3}{c}{ Unstructured play } & \multicolumn{3}{c}{ Screen time } \\
& $N$ & $\%$ & $N$ & $\%$ & $N$ & $\%$ \\
\hline 0 & 82 & 35.2 & 0 & .0 & 96 & 41.0 \\
1 & 86 & 36.9 & 2 & .9 & 85 & 36.3 \\
2 & 49 & 21.0 & 5 & 2.1 & 42 & 17.9 \\
3 & 9 & 3.9 & 19 & 8.2 & 9 & 3.8 \\
4 & 5 & 2.1 & 27 & 11.6 & 1 & .4 \\
5 & 1 & .4 & 44 & 18.9 & 1 & .4 \\
6 or more & 1 & .4 & 136 & 58.4 & 0 & .0 \\
\hline
\end{tabular}

\section{Parental perception}

Table 5 delineates the total score data from the eight item Play Perception Scale examining parental perceptions about the value of play in supporting development of children under the age of three years. As mentioned earlier, the Play Perception Scale contained eight questions relating to parental perceptions about the importance of play in supporting development. These were rated on a 5-point Likert scale ranging from strongly disagree (1) to strongly agree (5). Possible totals ranged from 8-40 and the higher a participant's overall score, the stronger they perceived free, unstructured play to best support development in the first three years. In contrast, the lower the score, the stronger the perception that structured play is most conducive to early development.

The total scores of parental perception were obtained by summing the answers given to the eight statements. The average reported parental perception score was $32.62(S D=4.17)$. Table 5 shows that the largest group of parents scored between 31-36 (49.9\%, $N=117)$ and $15.4 \%(N=36)$ scored between $37-39$. It was further identified that $29.4 \%(N=69)$ of parents scored between 25-30. Only 3.4\% $(N=8)$ provided the highest possible score of 40 . No 
respondent received a score lower than 21 and only $1.7 \%(N=4)$ of participants received a total score between 22-24.

\section{Table 5}

Total scores on the Play Perception Scale

\begin{tabular}{lrr}
\hline Parental perception total score & $N$ & $\%$ \\
\hline $8-21$ & 0 & .0 \\
$22-24$ & 4 & 1.7 \\
$25-27$ & 28 & 11.9 \\
$28-30$ & 41 & 17.5 \\
$31-33$ & 57 & 24.2 \\
$34-36$ & 60 & 25.7 \\
$37-39$ & 36 & 15.4 \\
40 & 8 & 3.4 \\
\hline
\end{tabular}

\section{Exploratory factor analysis}

Due to the development and use of a new scale, which was required to examine perceptions held by parents of children under the age of three years, it was considered important to examine the psychometric properties of the Play Perception Scale. Therefore, an EFA was undertaken to assess the components underlying the eight items within the scale. Prior to performing the EFA, the suitability of perception data (questions 12a-12h) for use in this manner was examined. The sample size of 234 respondents was considered appropriate. Examination of the correlation matrix revealed several coefficients above 0.3 and Bartlett's test of sphericity was significant $\left(\mathrm{X}^{2}(234)=28, p=0.000\right)$. Further, inspection of the Kaiser-Meyer Olkin measure of sampling adequacy $(\mathrm{KMO})$ revealed that the sample was factorable $(\mathrm{KMO}=0.756)$. Given these criteria were met, EFA was deemed appropriate (Pallant, 2007). A principle components analysis (PCA) revealed the presence of three components with Eigenvalues exceeding 1 explaining $35.7 \%, 16.3 \%$, and $12.8 \%$ of the variance respectively (see Table 6). An inspection of the screeplot revealed a clear break at the second component. It was therefore decided to retain two factors for further investigation. The two component solution explained a total of $52.4 \%$ of the variance with one component contributing $35.7 \%$ of the variance and the second contributing $16.3 \%$. 


\section{Table 6}

Component matrix initial analysis for PCA with forced four factor solution of parental perception items

\begin{tabular}{|c|c|c|c|c|}
\hline \multirow[t]{2}{*}{ Question } & & \multicolumn{3}{|c|}{ Component } \\
\hline & & 1 & 2 & 3 \\
\hline Q12h & $\begin{array}{l}\text { Structured play is more valuable to my child's } \\
\text { development than unstructured play }\end{array}$ & .73 & - & - \\
\hline Q12c & $\begin{array}{l}\text { Children aged } 0 \text {-three years require deliberate early } \\
\text { teaching to enable them to be school ready }\end{array}$ & .67 & -.49 & - \\
\hline Q12b & $\begin{array}{l}\text { Children aged } 0 \text {-three years require structured } \\
\text { activities to support development }\end{array}$ & .66 & -.56 & - \\
\hline Q12g & $\begin{array}{l}\text { It is important for my chid to have time to self } \\
\text { direct their play }\end{array}$ & .64 & .50 & - \\
\hline Q12a & $\begin{array}{l}\text { Unstructured playing time is also learning time for } \\
\text { my child }\end{array}$ & .60 & .44 & - \\
\hline Q12e & $\begin{array}{l}\text { It is important for my child to have unstructured } \\
\text { time outdoors }\end{array}$ & .54 & .51 & - \\
\hline Q12f & $\begin{array}{l}\text { Screen time (e.g. television, DVDs, and computer } \\
\text { use) is appropriate for my child }\end{array}$ & .36 & - & .78 \\
\hline Q12d & $\begin{array}{l}\text { Toys which have many uses better support child } \\
\text { development than toys which can only be used in } \\
\text { one specific way }\end{array}$ & .51 & - & .52 \\
\hline
\end{tabular}

To support the interpretation of these components, oblimin rotation was performed. The rotated solution revealed the presence of simple structure with both components revealing a number of strong loadings, with 7 of the 8 factors loading and each on only one component. The interpretation of these components was consistent with the intention of the survey, with structured play perception items loading strongly on component 1 and unstructured play perception items loading strongly on component 2 . These findings demonstrated a positive correlation between the two factors $(r=0.37)$. The results of this analysis support the use of structured and unstructured play perception items as separate scales (see Table 7). One item, question $12 \mathrm{f}$, did not load onto either component. This may be due to the fact that the question examined screen time, a topic which is separate from the components of structured or unstructured play. However, it was considered important to include such a question as a third component to be used in analysis due to the literature review suggesting that technological advancements have resulted in modern children spending significant amounts of time watching television or movies and playing on computers (Elkind, 2007; Zimmermann, et al., 2007). 
Subsequently, the internal consistency of the Play Perception Scale was tested using Cronbach's coefficient alpha. An alpha score of 0.70 was obtained which was considered acceptable and, as a result, suggested that the scale was suitable for use in this study (Pallant, 2007). 


\section{Table 7}

Patterns and structure matrix for PCA of oblimin rotation of two factor solution of parental perception items

\begin{tabular}{|c|c|c|c|c|c|c|}
\hline \multirow{2}{*}{\multicolumn{2}{|c|}{ Question }} & \multicolumn{2}{|c|}{ Pattern coefficient } & \multicolumn{2}{|c|}{ Structure coefficient } & \multirow[t]{2}{*}{ Communalities } \\
\hline & & Component 1 & Component 2 & Component 1 & Component 2 & \\
\hline Q12b & $\begin{array}{l}\text { Children aged } 0 \text {-three years require } \\
\text { structured activities to support } \\
\text { development }\end{array}$ & .90 & -.17 & .84 & .16 & .74 \\
\hline Q12c & $\begin{array}{l}\text { Children aged } 0 \text {-three years require } \\
\text { deliberate early teaching to enable them to } \\
\text { be school ready }\end{array}$ & .85 & -.10 & .82 & .22 & .68 \\
\hline Q12h & $\begin{array}{l}\text { Structured play is more valuable to my } \\
\text { child's development than unstructured play }\end{array}$ & .68 & .19 & .75 & .43 & .59 \\
\hline Q12f & $\begin{array}{l}\text { Screen time (e.g. television, DVDs, and } \\
\text { computer use) is appropriate for my child }\end{array}$ & .31 & .12 & .35 & .24 & .34 \\
\hline Q12g & $\begin{array}{l}\text { It is important for my chid to have time to } \\
\text { self direct their play }\end{array}$ & .00 & .81 & .30 & .81 & .65 \\
\hline Q12e & $\begin{array}{l}\text { It is important for my child to have } \\
\text { unstructured time outdoors }\end{array}$ & -.06 & .76 & .22 & .74 & .55 \\
\hline Q12a & $\begin{array}{l}\text { Unstructured playing time is also learning } \\
\text { time for my child }\end{array}$ & .03 & .73 & .30 & .74 & .55 \\
\hline Q12d & $\begin{array}{l}\text { Toys which have many uses better support } \\
\text { child development than toys which can } \\
\text { only be used in one specific way }\end{array}$ & .31 & .32 & .43 & .43 & .27 \\
\hline
\end{tabular}


A composite score was then created for each of the factors based on the mean of the loaded items. These totals were used as the dependent variables in subsequent analysis tests. Since the items on which the factors were based ranged in value from 1-5, the factors themselves ranged from 1-5. The higher the mean score, the higher the perception that unstructured play best supports child development during the first three years of childhood. In contrast, the lower the score, the higher the perception that structured play is most conducive to early learning.

Table 8 outlines the number of items, mean, and standard deviation of the three components as well as the skewness and kurtosis. The skewness of the unstructured play perception component was significantly $(p=<0.05)$ less than 0 , as was the kurtosis of the screen time perception component. This indicates that the data did not meet the distributional assumptions for normality. However, in both cases, as well as for the structured play perception component, histograms followed an approximately normal shape and, as the sample size is over 200, normal theory tests (t-tests and analysis of variance) can be used for analysis (Field, 2009).

\section{Table 8}

Descriptive statistics for the EFA components

\begin{tabular}{lccrr}
\hline Component & No. of Items & $M(S D)$ & $\begin{array}{r}\text { Skewness } \\
\text { (std. error) }\end{array}$ & $\begin{array}{r}\text { Kurtosis } \\
\text { (std. error) }\end{array}$ \\
\hline Structured play perception & 3 & $3.67(0.90)$ & $-0.17(0.16)$ & $-0.75(0.32)$ \\
Unstructured play perception & 4 & $4.55(0.44)$ & $-0.73(0.16)$ & $-0.55(0.32)$ \\
Screen time perception & 1 & $3.42(1.09)$ & $0.03(0.16)$ & $-1.16(0.32)$ \\
\hline
\end{tabular}

\section{Play and screen time perception}

The eight independent variables were: the time children spent involved in structured play; the time children spent in unstructured play; the number of hours engaged in screen time; the number of activities engaged in during an average week; parent age; parent qualifications; child age; family type including whether children were only children or had siblings. The three dependant variables comprising the three EFA components of perception were: structured play perception; unstructured play perception; screen time perception. In order to investigate the relationships between these variables, t-tests and one-way analysis of variance (ANOVA) were used. 


\section{Structured play hours and structured play perception}

Based on the literature, which suggests a relationship between parental perception and the hours children spend involved in play, the relationship between the amount of hours children spent in structured play activities during an average day and parents' structured play perception was examined (Fisher, et al., 2008; Stipek, et al., 1992). In order to achieve this, a t-test was conducted. Participant responses for hours their child spent involved in this form of play were split into low and high groupings and these were then compared against parental perception about structured play. Groupings were determined by ensuring a minimum of 30 participants were in each group in order to minimise difference in size and ensure validity of findings. Further, these groupings aimed to effectively reflect the split in participant responses. As Table 9 shows, parents whose children spent fewer hours (0-1) involved in structured play time had significantly lower perceptions that structured play supports the development of children under three years of age. In contrast, parents whose children were involved in higher amounts of structured play ( 2 or more hours) valued this form of play more highly than unstructured or free play $\quad(t=6.62, d f=213, p=<0.0005)$.

\section{Table 9}

Structured play hours and structured play perception

\begin{tabular}{lr}
\hline Structured play hours & Structured play perception \\
& $M(S D)$ \\
\hline Low: 0 - 1 hours $(N=168)$ & $3.89(0.84)$ \\
High: 2 or more hours $(N=65)$ & $3.09(0.80)$ \\
\hline
\end{tabular}

\section{Unstructured play hours and unstructured play perception}

Also based on the research by Fisher et al. (2008) and Stipek et al. (1992), the mean relationship between the amount of hours during an average day children spent involved in unstructured play and participants' unstructured play perception was examined. In order to achieve this, a second t-test was run. Once again participant responses for hours their child spent involved in this form of play were split into low and high groupings with a minimum of 30 participants in each group to ensure validity and to best reflect participant responses. These groups were then compared against parental perception about unstructured play. As indicated in Table 10, findings show that there was a significant mean difference which suggests that parents 
whose children engaged in high amounts of unstructured play time (5 or more hours) during an average day perceived this type of play to be more valuable than parents whose children engaged in less unstructured play (under 4 hours) $(t=-3.69, d f=231, p=<0.0005)$. However, the mean difference for these variables is less than that found in the first test examining structured play perception and time.

\section{Table 10}

Unstructured play hours and unstructured play perception

\begin{tabular}{lr}
\hline Unstructured play hours & Unstructured play perception \\
& $M(S D)$ \\
\hline Low: 0 -4 hours $(N=53)$ & $4.35(0.47)$ \\
High: 5 or more hours $(N=180)$ & $4.60(0.42)$ \\
\hline
\end{tabular}

\section{Screen time hours and screen time perception}

A further t-test was conducted in order to examine the number of hours children spent in screen time during an average day and parental perception about the appropriateness of this activity for children under three years of age. This relationship was considered important to analyse because there appears to be a gap in the literature surrounding the influence of parental perception on children's exposure to screen time despite the large amount of research undertaken examining the effects of early exposure on young children. Responses regarding the number of hours were once again split into low and high groupings. This split was determined in a way that would best reflect the amount of time children spent in this activity as well as ensuring validity through group size. As can be seen from the mean findings outlined in Table 11, parents whose children were exposed to lower hours (0-1) of screen time during an average day perceived this activity to be significantly less appropriate for their child than parents whose children were exposed to higher amounts ( 2 or more hours) $(t=6.91, d f=107.41, p=<0.0005)$. 


\section{Table 11}

Screen time hours and screen time perception

Screen time hours

Screen time perception

$M(S D)$

Low: 0-1 hours $(N=181)$

High: 2 or more hours $(N=53)$

$2.68(0.83)$

\section{Number of weekly activities and play perception}

One-way ANOVA was conducted in order to examine any mean differences between the number of activities children engage in during an average week and parental perception. It was deemed important to examine this relationship due to prior research identifying the link between parental perceptions and the types of activities in which children engage (Fisher, et al., 2008; Stipek, et al., 1992). The analysis of the relationship between parental play perception and the number of activities aimed to provide an alternative dimension to these earlier findings. Three groupings were created by splitting the number of activities. These were determined by ensuring a minimum size of 30 per group and by aiming to effectively reflect the number of activities from a low amount per week to a high amount. The means of these three groups were then compared to the means of the three types of parental perception. Significant mean differences were determined when examining the number of activities against structured play perception. As Table 12 indicates, the more activities a child engaged in per week the more parents perceived that structured time best supported early learning and, in contrast, the fewer activities a child engaged in the less structured play was valued by participants $(F(2,230)=6.91, p=0.001)$. Post-hoc tests revealed that these significant mean differences were between the $0-1$ activity group and the remaining two higher activity groups. Findings indicated no significant differences between activities and unstructured play perception $(F(2,230)=0.22, p=0.802)$ or screen time perception $(F(2,230)=2.61, p=0.076)$. 


\section{Table 12}

Number of weekly activities and play perception

\begin{tabular}{lrrr}
\hline Number of weekly activities & $\begin{array}{r}\text { Structured play } \\
\text { perception }\end{array}$ & $\begin{array}{r}\text { Unstructured play } \\
\text { perception }\end{array}$ & $\begin{array}{r}\text { Screen time } \\
\text { perception }\end{array}$ \\
& $M(S D)$ & $M(S D)$ & $M(S D)$ \\
\hline $0-1$ activities $(N=76)$ & $3.98(0.90)$ & $4.56(0.47)$ & $3.63(1.07)$ \\
2 activities $(N=77)$ & $3.54(0.91)$ & $4.52(0.44)$ & $3.39(1.09)$ \\
3 or more activities $(N=80)$ & $3.51(0.81)$ & $4.57(0.43)$ & $3.24(1.09)$ \\
\hline
\end{tabular}

\section{Parent age and play perception}

A second one-way ANOVA was conducted in order to determine mean relationships between parent age and parental perception. This relationship was chosen for examination due to a gap in research as to whether parent age influences perception. Three factors were created for this independent variable in order to reflect parent age ranging from younger parents to middle aged parents through to older parents. A minimum of 30 participants were in each group in order to minimise difference in size and ensure validity of findings. These groups were then compared to parental perception. A significant difference in mean scores was identified between parent age and structured time with younger parents valuing this form of play more highly than older parents $(F(2,231)=3.23, p=0.041)$. On examination of the post-hoc tests, the youngest age group (29 years or under) had a significantly different mean from those aged 40 years or older. However, no significant differences between the mean scores were found when examining parent age and unstructured play perception $(F(2,231)=1.62, p=0.201)$ or parent age and screen time perception $(F(2,231)=0.88, p=0.417)$.

\section{Table 13}

Parent age and play perception

\begin{tabular}{lrrr}
\hline Parent age & $\begin{array}{r}\text { Structured play } \\
\text { perception }\end{array}$ & $\begin{array}{r}\text { Unstructured play } \\
\text { perception }\end{array}$ & $\begin{array}{r}\text { Screen time } \\
\text { perception }\end{array}$ \\
& $M(S D)$ & $M(S D)$ & $M(S D)$ \\
\hline 29 years or under $(N=34)$ & $3.36(0.97)$ & $4.46(0.40)$ & $3.65(1.07)$ \\
$30-39$ years $(N=164)$ & $3.68(0.90)$ & $4.55(0.44)$ & $3.38(1.08)$ \\
40 years or older $(N=36)$ & $3.90(0.76)$ & $4.65(0.49)$ & $3.36(1.15)$ \\
\hline
\end{tabular}




\section{Parent qualifications and play perception}

The demographic characteristic of parent qualification has previously been recognised in research as an influence impacting parental perception about the value of play during early childhood (Stipek, et al., 1992). As a result, a t-test was run in order to further examine this relationship and determine if there were any significant mean differences between parent qualification levels and the perceptions they held in regards to the two types of play and screen time. Qualification type was split into two groups. The first included participants with a school qualification or less and the second included participants with a tertiary qualification. A minimum of 30 participants were in each group in order to minimise difference in size and ensure validity of findings. These two groups were then compared against the three factors of parental perception. In relation to structured play perception, results indicated that parents who held a school qualification or less valued structured play for their child significantly more than those who held a tertiary qualification $(t=-2.94, d f=230, p=0.004)$. Similar significant findings were identified when examining unstructured play perception and education levels, with more educated parents valuing unstructured play more highly than those with a lower qualification $(t=-2.18, d f=230, p=0.030)$. No significant differences in mean scores were found when testing parent education against perceptions about the appropriateness of screen time for children under three years of age $(t=-0.64, d f=230, p=0.523)$.

\section{Table 14}

Parent qualifications and play perception

\begin{tabular}{lrrr}
\hline Qualification & $\begin{array}{r}\text { Structured play } \\
\text { perception }\end{array}$ & $\begin{array}{r}\text { Unstructured } \\
\text { play perception }\end{array}$ & $\begin{array}{r}\text { Screen time } \\
\text { perception }\end{array}$ \\
& $M(S D)$ & $M(S D)$ & $M(S D)$ \\
\hline School qualification or less $(N=45)$ & $3.33(0.98)$ & $4.43(0.43)$ & $3.33(1.04)$ \\
Tertiary qualification $(N=187)$ & $3.76(0.86)$ & $4.59(0.44)$ & $3.45(1.10)$ \\
\hline
\end{tabular}

\section{Child age and play perception}

A one-way ANOVA was conducted in order to understand the mean differences between child age and parental perception. This time four groups were created for child age and this split was determined in a way that would ensure a minimum of 30 children per group as well as to best reflect age range from babies through to toddlers under the age of three years. The mean of 
each of these groups was then compared with the mean of the three parental perception factors. Like parent age, the demographic variable of child age has not been previously examined in research focusing on parent perceptions about play. The current study therefore aims to fill this gap through such analysis. As shown in Table 15, significance was determined between the age of the child and screen time perception with participants deeming this activity less appropriate for younger children and becoming more appropriate for older children $\quad(F(3,229)=10.20, p$ $=<0.0005)$. Post-hoc tests revealed that the two younger groups of children aged 18 months or under and 19-24 months had a significantly different mean score when compared to the two older groups aged 25-30 months and 31-35 months. No significant differences were found between the mean scores of child age and structured play perception $(F(3,229)=0.55, p=$ $0.647)$ or unstructured play perception $(F(3,229)=1.42, p=0.239)$.

\section{Table 15}

Child age and play perception

\begin{tabular}{|c|c|c|c|}
\hline Child age & $\begin{array}{r}\text { Structured play } \\
\text { perception } \\
M(S D)\end{array}$ & $\begin{array}{r}\text { Unstructured play } \\
\text { perception } \\
M(S D)\end{array}$ & $\begin{array}{r}\text { Screen time } \\
\text { perception } \\
M(S D)\end{array}$ \\
\hline 18 months or under $(N=59)$ & $3.62(0.95)$ & $4.56(0.43)$ & $3.93(0.94)$ \\
\hline $19-24$ months $(N=54)$ & $3.69(0.85)$ & $4.53(0.43)$ & $3.63(0.10)$ \\
\hline 25-30 months $(N=70)$ & $3.61(0.87)$ & $4.48(0.48)$ & $3.13(1.05)$ \\
\hline $31-35$ months $(N=50)$ & $3.81(0.93)$ & $4.65(0.41)$ & $3.00(1.14)$ \\
\hline
\end{tabular}

\section{Family type and play perception}

Family type is a final demographic factor chosen for examination. This variable has not been examined in prior research and it was considered important to analyse alongside parental perceptions due to qualitative feedback from participants. For example, some parents stated that their first child received more structured experiences compared with younger siblings. As Table 16 shows, a t-test was run in order to determine any significant differences in mean scores between parental perception and the family types including whether a child was an only child or had siblings. Two factors were created by grouping only children and all those who had siblings. Once again a minimum group size of 30 was obtained in order to ensure validity. These groups were then compared against the dependant variables of parental perception. However, no 
significant differences were determined between family type and structured play perception $(t=-0.47, d f=97.63, p=0.641)$, unstructured play perception $(t=0.71, d f=231, p=0.476)$ or screen time perception $(t=1.36, d f=231, p=0.174)$.

\section{Table 16}

Family type and play perception

\begin{tabular}{lrrr}
\hline Family type & $\begin{array}{r}\text { Structured play } \\
\text { perception }\end{array}$ & Unstructured play & $\begin{array}{r}\text { Screen time } \\
\text { perception }\end{array}$ \\
$M(S D)$ & $M(S D)$ & $M(S D)$ \\
\hline Only child $(N=53)$ & $3.63(0.79)$ & $4.59(0.39)$ & $3.60(1.13)$ \\
With siblings $(N=180)$ & $3.69(0.92)$ & $4.54(0.46)$ & $3.37(1.07)$ \\
\hline
\end{tabular}

\section{Qualitative data}

The qualitative statement at the end of the survey asked respondents to make further comments on the importance of structured and unstructured play. Using a process of thematic analysis, in which each response was clustered into groups by two independent raters, five key themes emerged. These were developmental shift and birth order, the value of both structured and unstructured play in supporting development, imagination, definitions of play and the role of the parent, and screen time.

\section{Developmental shift and birth order}

A number of respondents believed there is a developmental shift during early childhood whereby children require different play opportunities as they grow. For example, a number of participants stated that in the first three years of childhood unstructured play is most conducive to supporting the natural development and significant growth that occurs during this time. As children grow beyond this into preschool age, and then move into formal education at school, more structure is appropriate. This form of structured play was believed to enable older children to learn concepts such as counting and reading required to succeed in the academic environment of primary school. A number of parents also commented that children spend enough time engaged in structured activity during the school years and when entering the workforce as adults. These parents believed that early childhood was therefore a time for children to learn through meaningful and freely chosen play experiences. 
"There is nothing a child under three years old needs structured time to learn. It is nice for 3-5 year olds to have a balance or some structured time but there is plenty of time at school for structure. Under three year olds are still babies and need one-to-one attachments and free play to explore their environments."

An expansion of this first theme came from participants stating that birth order can affect parenting choices and the consequent type of play a child predominantly experiences. For example, it was argued that the first child in a family is often exposed to more structured, adult led play than subsequent younger children who are often left to engage in unstructured play with their siblings and less adult involvement. It was suggested that this could be partly due to parents gaining confidence as they become older and more experienced in their role and in their knowledge of child development, as well as the obvious rationale that children with siblings have peers to play with unlike only children who may rely more heavily on adult company.

"I know I spent far more time with my first born doing puzzles together and playing than I do with my youngest son who has his older brothers to entertain him."

\section{The value of both structured and unstructured play in supporting development}

The second theme to emerge was that there is a place for both structured and unstructured play during the first three years of childhood and that both offer positive outcomes in supporting different aspects of development. For example, unstructured play was believed to foster creativity and learning through children following their own interests and agendas. Participants also commented that this form of play supports the development of social skills, such as forming relationships and developing empathy, as well as fostering self confidence. In contrast, structured play was stated to support more specific cognitive learning and deliberate teaching of new knowledge such as the alphabet, counting, and colours. However, this type of play was also suggested to encourage the growth of social skills including learning rules, sharing, and co-operation.

"I believe unstructured play is vital for small children to discover their world and their capabilities firsthand, provided they have an interesting and stimulating environment to play in. They also still need gentle guidance, boundaries, and discipline in which to discover their world. Structured play is important for teaching concepts such as colours, shapes, reading, and word association etc. Both structured and unstructured learning has its place for the first three years of a child's life." 
"They (structured and unstructured play) serve different purposes and can compliment each other. Free play provides open ended opportunities to develop children's creativity that isn't limited by adults' ideas and values. Structured play can provide opportunities and exposure to activities that free play wouldn't usually have access to."

\section{Imagination}

The third theme to come out of the thematic analysis was the value of play, especially free or unstructured play, in fostering children's imaginations during the first three years of life. For example, it was stated that when children are offered time to engage in play which is led by their own choices, ideas, and interests they will be supported to develop their creativity and imagination. Further, when play is free and involves less adult involvement aimed to encourage specific learning outcomes to be achieved, children are able to become fully engaged in their chosen experiences and use their imaginations to take the play in whatever direction they choose.

"Unstructured play lets my daughter use her imagination more. The more structured the play is, the more direction she gets and the less her wee whims and ideas come to the fore."

\section{Definitions of play and the role of the parent}

The fourth theme saw some questioning from participants about the provided definitions of the two types of play. While a large number of participants supported child led play in supporting natural learning, comments were made about the importance for parents to be present and available to guide children when necessary rather than being either fully absent or, in contrast, overly involved. Participants suggested the importance of setting up the environment or providing learning experiences for their children and then allowing the children to play in their own way and explore the environment as they choose. These comments prompt questions around the role of the parent in supporting children's play and consequent learning. For example, while unstructured play was defined as being child led with no set rules or outcomes, participants suggested that they may still be present as they observe their child at play and are available to offer support if required. These comments also suggest that, rather than structured and unstructured play being viewed as completely separate types of play, it may be beneficial to view them on a continuum. For example, the extremes of unstructured and structured play may sit at opposite ends of a continuum with adult involvement and eventual deliberate teaching 
gradually increasing and child led play, where children are free to follow their own agendas and interests, gradually decreasing.

"I prefer to let my child lead his own learning. He can focus his attention where it interests him most and I support this. I try to provide as many new experiences as I am able, particularly around his area of interest."

"Even when play is unstructured an adult can still act as an educator and enrich the learning through the medium of play. My view is that unstructured play does not mean an adult isn't involved, it is just child led."

\section{Screen time}

The final theme to emerge from the responses given to the qualitative statement was around screen time, involving television, DVD, and computer use. Most participants who commented on this suggested it was only appropriate in small amounts and agreed that as well as being limited, the types of screen time offered should be monitored by an adult in order to ensure its suitability for children. Screen time was also considered a resting time for children in between play time, outings, and routine activities such as meal time, toileting or bathing. Several participants commented that it provides parents with valuable time and space to get jobs done such as cooking dinner.

"I can see how a lot of screen time could disadvantage a child as they are not really exploring or learning in their own way. However, I do let my daughter watch some television as a sort of down time for her and for me!"

\section{Summary of findings}

The quantitative and qualitative findings to come out of the survey offered insight into the value participants place on structured play, unstructured play, and screen time for their children as well as the demographic information that may influence these beliefs and the impact this has on a child's daily experiences. As hypothesised, the major quantitative finding to emerge from this study was that parental perception influenced the way in which children spent their time. For example, it was found that parents whose children engaged in higher amounts of structured, adult led experiences valued this type of play more highly than parents whose children engaged less in this form of play. In contrast, parents who valued unstructured play more highly offered more opportunities for their child to engage in this form of play over 
structured activities. Further, parents whose children engaged in lower daily amounts of screen time perceived it to be less appropriate for their child than parents whose children were exposed to higher amounts of television and DVD viewing as well as computer use.

Another finding was that older parents did not value structured play as highly as younger parents. However, no significance was identified when examining parent age against unstructured play or screen time perceptions. Parents who were less educated valued structured play more highly than those with a tertiary qualification. The parents with a higher qualification perceived unstructured play to be more appropriate for children under three years old. No significant difference was found between parent education and screen time perception. In regard to the demographics of the child, it was found that the age of the child influenced parental perceptions around the appropriateness of screen time. For example, the younger the child the less parents deemed this activity to be appropriate. The older the child, the more acceptable it was perceived to be. No significance was found when examining child age with structured and unstructured play perception or family type with any of the three perception factors. However, on examination of weekly activities, it was found that the more activities a child engaged in, the higher structured play was valued by parents. In contrast, the fewer activities a child engaged in, the lower the perception that structured play is most conducive to supporting the development of infants and toddlers.

Five key themes emerged from the qualitative findings. The first was that a developmental shift occurs as children grow and, as a result, different forms of play experiences are required to support such development. As part of this first theme, participants also mentioned that birth order can influence the types of play opportunities to which a child is exposed. The second theme related to the belief that both structured and unstructured play can be valuable in supporting development and that the two types offer children unique and important learning opportunities. The development of imagination was the third theme to emerge and was believed to be especially fostered through unstructured play experiences. The fourth theme was a discussion around the definitions of the types of play and the role of the parent in setting up the space and being available and involved but not domineering. The final theme to emerge from the qualitative findings was the appropriateness of screen time for children under the age of three years. 


\section{CHAPTER FIVE: DISCUSSION}

\section{Introduction}

The aim of this study was to determine parental perceptions about the value of play for children under three years of age and the influence these views have on the types of play, structured or unstructured, that infants and toddlers engage in and how they spend their time. The results of this research suggest that play perceptions relate to the types of choices parents make in regard to their child's daily experiences. These findings were identified through analyses of participant responses to the survey.

The specific focus area of this study has received little prior research. However, the present study found that perceptions vary to a degree around which sort of play, either structured or unstructured, best supports optimal child development during the first three years of life. This is in line with current literature discussing the debate of the hurried child, a modern phenomenon which is now believed to be greatly influencing childhood and the early experiences of many infants, toddlers, and young children. However, the majority of participants from this study valued unstructured play highly and chose to offer these forms of child led experiences to their children more frequently than structured play activities. Parental perceptions about the appropriateness of screen time also varied yet findings concur with previous research suggesting that parents believe television, DVD, and computer use is more appropriate as the child grows older. Another finding from the current study that is supported by prior research is that education levels of parents can influence their perceptions about the value of play and its role in fostering development. New findings to emerge from this study suggest that parent age and child age also influence parental perceptions and beliefs.

The following discussion is delineated into five sections. The first discusses the key findings in relation to the study's four research questions. The second examines the methodological contributions this study makes to the field of early childhood. The third addresses the limitations of the study and offers recommendations for future research in the area. The fourth identifies the theoretical and applied implications of the study in relation to four areas which are the role of the parent, early childhood education, parent education, and child development and wellbeing. The discussion will conclude with a summary of the study. 


\section{Research questions 1 and 2: The extent to which parents value structured and unstructured play}

The first research question asked to what extent parents valued structured and unstructured play in supporting their young children's learning and development. The findings from this study identified that the majority of children engaged in little structured play on a daily basis. Furthermore, most parents did not place a high value on structured play. However, the qualitative results revealed that those parents who did value structured play did so for its capacity to teach specific cognitive learning such as the alphabet, counting, and colours as well as to encourage the development of specific social skills through adult involvement, including learning rules, sharing, and co-operation.

In relation to the extent to which parents valued unstructured play in supporting development, the study found that children engaged in this type of play for a much greater average time per day than structured play. In relation to parental perception, this free play was valued highly by the majority of participants. Qualitative data gathered in this study expanded understanding of parental perception around the value of this form of play. Participants acknowledged that when children engage in freely chosen experiences, which are led by their own interests and agendas, their creativity and imagination is fostered. Bergen (2002) states that when children have opportunities to engage their creativity through imaginary play, they are building the foundational cognitive skills which can lead to abstract and higher order thinking in adulthood. Participant comments reflected the perception that unstructured play supports the development of self confidence as well as the social skills of forming relationships and developing empathy. These findings suggest that play in general terms is valued by participants and this is in line with previous research undertaken in the field. For example, a number of earlier studies examining the perceptions held by parents and early childhood educators about the role of play identified it as being a valued and significant way in which young children's holistic development is promoted (Fisher, et al., 2008; Haight, et al., 1997; Izumi-Taylor, et al., 2010; Rothlein \& Brett, 1987; Sandberg \& Samuelsson, 2005; Stipek, et al., 1992).

Research specifically examining perceptions in relation to these two types of play is limited, especially when examined against the beliefs and attitudes held by parents with children under the age of three years. The findings from this study indicate that unstructured play is perceived as most conducive to the learning, development, and wellbeing of infants and toddlers. 
This is evident in the limited amount of daily hours the focus children spent involved in structured play compared with unstructured play time, as well as the limited amount of total weekly activities attended by most children. This data regarding the specific type of play parents value contrasts with the small amount of prior research examining this topic. For example, a study conducted by Fisher et al. (2008) in the U.S. which surveyed perceptions of 1130 mothers with children under 5 years, found that formalised and goal orientated activities were believed to be more conducive to developing academic ability in children compared with unstructured play. Similarly, research conducted by Jensen (2002) which involved 3000 parents in five countries with children between 0-12 years, identified that structured play was more highly valued. This was due to parental belief that it better enables children to grow into successful and competent adults later in life. While both of these studies examined structured and unstructured play in relation to parental beliefs, neither of them focused on the specific younger age range of this study which may offer possible insight into the contrast in findings.

The results from this study highlight that participants valued unstructured play more highly than structured play. This finding is in contrast to the growing phenomenon known as the hurried child whereby children are believed to be experiencing an upbringing with greater structure and adult intervention than previous generations. The value of unstructured play in promoting natural development is considered to be under threat and not as highly regarded by society as it once was (Elkind, 2007; Gleave, 2009; Gray, 2011; Hewes, 2006; Nicolopoulou, 2010; Spodek \& Saracho, 2003). Literature suggests that this shift may be due to increasing pressure on caregivers to prepare young children for the academic demands of formal education and adult life as well as due to the technological advancements which are believed to be occupying increasing amounts of children's time (Almon, 2004; Elkind, 2007; Gleave, 2009; Hewes, 2006; Nicolopoulou, 2010; Zigler \& Bishop-Josef, 2006). The creation of educational toys and programmes designed specifically to teach infants and toddlers cognitive skills, such as Baby Einstein ${ }^{\mathrm{TM}}$ and Your Baby Can Read ${ }^{\mathrm{TM}}$, shows that this trend is beginning to affect even the youngest members of society (Elkind, 2007). However, a plausible rationale for the findings within this study may be that these changing societal values and perceptions have not influenced the majority of parents involved in this study. This may also be a result of the sample group which was comprised of Playcentre parents who may have been educated around the importance of play, especially unstructured and child directed play, in promoting early learning. This 
conjecture is based on the concepts of parent education around child development and parents as first teachers which are fundamental underpinnings of Playcentre's organisational philosophy (Playcentre New Zealand, 2012b).

\section{Research question 3: The relationship between perceptions and time}

This study identified a relationship between parental perception and the types of play in which their young children engage. When analysing structured play hours against structured play perception, it was found that, parents whose children were involved in higher amounts of structured play valued this form of play more highly than unstructured or free play. This finding confirms the study's first hypothesis which states that parents who score highly on the Play Perception Scale regarding the importance of structured play in the first three years will prioritise structured time over unstructured time for their children.

Analysis examining unstructured play time and perception suggest a similar relationship between these two sets of variables. Parents whose children engaged in high amounts of unstructured play time during an average day perceived this type of play to be most valuable. This finding confirms the study's second hypothesis which states that parents who score highly on the Play Perception Scale regarding the importance of unstructured play in the first three years will prioritise time for child initiated unstructured play and limit structured time.

These two confirmed hypotheses align with two similar pieces of research which found significant relationships between the beliefs and attitudes held by parents and the types of activities in which their children engaged. The first study to examine this relationship in regards to maternal perception found that mothers who valued play as a meaningful and natural way for children to learn reported that their children spent more time involved in play behaviours and activities than mothers who did not value play as highly as a tool to elicit meaningful learning (Fisher, et al., 2008). The second piece of research was by Stipek et al. (1992) and surveyed 551 parents in the U.S. with children aged 4-5 years who attended some form of early childhood education. It revealed a similar consistency with the current study between parents' beliefs about appropriate education and the reported types of activities engaged in by their children at home. Parents who valued adult led teaching strategies, that are comparable to structured play, practiced more formal parenting practices such as using flashcards and workbooks with their 
children. In contrast, parents who valued less formal parenting techniques, that are comparable to unstructured play, encouraged more child led learning to occur (Stipek, et al., 1992).

The EFA, which examined the psychometric properties of the Play Perception Scale, identified screen time perception as a separate component from the structured and unstructured play perception of parents. As a result, and because the appropriateness of television, DVD, and computer use for young children is recognised as a controversial topic in literature, the influence of parent perception in relation to screen time and the amount of time children spend involved in this activity was examined in the current study. Research has linked early childhood exposure to electronic media with the development of attentional problems in middle childhood (Christakis, et al., 2004). A further study has revealed that such exposure can result in a lack of academic success for children, as well as an inability to problem solve or creatively think due to mental and physical passivity, and an increase in impulsive behaviours (Healy, 1991; Shin, 2004).

Within this current study it was found most children were exposed to a relatively small amount of screen time, if any, during an average day. In relation to perception, parents whose children were exposed to lower hours of screen time perceived this activity to be significantly less appropriate for their child than parents whose children were exposed to higher daily amounts. No prior research looking specifically at parental perception and children's exposure to this activity could be identified and, as a result, these findings offer an interesting insight into the influence parental beliefs may have on children's media exposure during the first three years of childhood. It has been argued that the apparent decrease in free play opportunities for children is partly due to the growing popularity of, and exposure to, screen time for young children (Almon, 2004). However, the current study does not clearly support this argument as most of the parent participants exposed their child to a low amount of daily screen time and the average number of hours involved in free play was high.

In summary, it appears that parental perception did influence the way in which children spent their time. This finding raises some implications around the significant role of the parent in influencing the early experiences of infants and toddlers under the age of three years. For example, parents who believe, due to their own understandings and knowledge, that structured play is the most effective way to support early learning and development appear to expose their children to far greater amounts of formal and adult led activities. In contrast, parents who value the natural development fostered through unstructured experiences appear to offer their child 
plenty of time to self direct their own play and consequent learning. A similar relationship is evident from the findings in relation to screen time with parents who value it as appropriate for young children offering more time for their child to engage in this activity compared with caregivers who do not feel it is a suitable activity for their young child.

\section{Research question 4: The relationship between demographic factors and parental perception}

The first demographic factor that was examined in this study against the three parental perception factors was the age of the parent. This relationship was analysed because it has not been previously discussed in research surrounding the topic. Therefore, an aim of this study was to fill this gap in order to offer insight into whether parental age influences perception and consequent child rearing practices. Findings indicated that parental age was associated with structured play perception with younger parents, aged 29 years and under, valuing this form of play more highly than older parents, aged 40 years and over. A possible explanation for this finding may be the reported shift in societal values with a growing emphasis on the need for early formal learning and academics. Research by Rosenfeld examining this phenomenon found that opportunities to engage in unstructured and free play experiences had diminished by $50 \%$ in the past decade (as cited in Almon, 2004). This is believed to be due to a rise in popularity of structured and formalised learning experiences which is associated with increasing pressure on parents and early childhood educators to teach young children specific cognitive skills in order to better prepare them for the increased assessment requirements of formal education (Elkind, 2007; Milteer \& Ginsburg, 2012; Zigler \& Bishop-Josef, 2006). Younger parents could be more influenced by this recent shift as they may have experienced greater structure in their own childhoods. In contrast, older parents may have experienced more free play in their upbringing. Therefore, they could be inclined to encourage this for their own children in the belief that there is value in the traditional pedagogical underpinnings of free play (Fleer, 2011). Qualitative data may also offer a plausible explanation for the differing perspectives held by older and younger parents. Participants with more than one child recognised that as they became older, more confident, and experienced in their role as a caregiver they tended to relax more. With this came a greater trust in the naturally unfolding development of their child and a lessening of the belief that children require adult led and structured experiences to learn. Parenthood is acknowledged 
in literature as being a challenging role which can offer endless opportunities for personal growth and learning. The importance of questioning and reflecting on caregiving practices is recognised along with the need for parents to learn to trust their intuition about what is best for themselves and their children whilst simultaneously striving to deepen their own knowledge (Dancy, 2000).

A second demographic influence on perception examined in this study was that of parental education levels. The findings showed that parents who held a school qualification or less valued structured play more highly than parents who had a diploma, bachelor degree or postgraduate qualification. The latter group favoured unstructured play for their infants and toddlers. This is in support of the findings from research undertaken by Stipek et al. (1992) who identified that parents with a higher form of qualification advocated for less formal parenting and education techniques and were critical about the value of formalised and didactic teaching methods. These views are supported by research examining brain development in the first three years which is believed to lay the foundations for learning and experiences (Fancourt, 2004). Frost et al. (2008) argues that when children receive too much direct instruction, which is a trait of adult led structured play experiences, the brain development of a child can be negatively affected. However, meaningful play has been recognised as being one of the key experiences necessary for healthy development and the programming of neural structures during early childhood. It is noted that one of the rationales participants gave in their qualitative comments was that structured play activities are important as they enable children to be taught specific skills they would not otherwise learn. However, research examining teacher and child directed play episodes in the Slovak Republic, where 51 children were observed, found that children who were exposed to a free play based philosophy of education were more likely to develop an enhanced cognitive ability than those who were exposed to a more formal and structured one (Gimtrova \& Gimtrov, 2003).

The final demographic factor which revealed significant findings in this study was the relationship between the age of the child and parental perception in relation to screen time. Findings showed that participant perceptions around the appropriateness of screen time depended upon the age of the child. The younger the child the less appropriate it was considered; the older the child the more appropriate. An earlier study conducted by Zimmermann et al. (2007) in the U.S., which surveyed approximately 1000 parent participants, examined the amount of screen time in which infants and toddlers engaged. The study suggested that children of this age were 
exposed to large amounts of time involved in this activity and that these hours increased as children become older. The research found that by 3 months of age approximately $40 \%$ of the 1000 children surveyed watched 1 hour or more of television per day and this number rose to 90\% for children aged 2 years (Zimmermann, et al., 2007). It is interesting to consider the screen time findings from the current study as well as the Zimmerman et al. (2007) study in relation to the guidelines laid out by the American Academy of Paediatrics (2011). These recommendations state that due to the possible negative affects of screen time on infants and toddlers, the exposure to these forms of media should be avoided for children under the age of 2 years and limited for older preschool children (American Academy of Pediatrics, 2011).

Qualitative data in this study found that screen time was only deemed appropriate for infants and toddlers in limited amounts and that the types of media offered should be monitored by an adult in order to ensure suitability. These comments, as well as the shift in parental perception in relation to child age, suggests that the participants may be aware of some of the possible negative influences of screen time for children under the age of three years although it would be worthwhile to investigate the rationales behind these perceptions in order to determine this more clearly. This could be a focus for future research.

\section{Methodological contributions to the field}

Two key methodological contributions to the field of early childhood research emerged from this study. The first comes from conducting a study of this type in an area that is considerably under-researched, especially when exploring the views held by parents of infants and toddlers in relation to the value of play. Specifically, the present study examined structured and unstructured play alongside parent attitudes and how children spend their time. Consequently, this study offers unique insight into parental perceptions about the role of structured and unstructured play in promoting the learning and development of children under the age of three years. This foundational knowledge can be utilised as a basis for future research.

The second major contribution is the development of a new scale, called the Play Perception Scale, which was required in order to examine perceptions held by the specific parent group. To establish some initial psychometric information, an EFA was conducted on the scale. This process enabled the components underlying the eight items within the Play Perception Scale to be established. Results from the EFA indicated that parental perception towards play 
was a multi-dimensional construct composed of two factors. These factors related to perceptions associated with free, unstructured play and perceptions associated with structured play. One question from the scale relating to screen time did not load onto one of the two components and, as a result, was utilised in the analysis as a third factor. Although this analysis provided some information about the construct validity of the scale, further psychometric testing is recommended in order to measure both the reliability of the scale and the other types of validity. With this, the newly developed Play Perception Scale can be utilised in future survey research related to this field of study.

\section{Limitations and future research}

The main limitation of the study is the use of a non-probabilistic convenience sample, rather than a random sample, resulting in a risk of selection bias whereby findings cannot be generalised to the whole population of parents within New Zealand (Johnson \& Christensen, 2008). Instead they are limited to the perceptions held by this specific group of 234 participants and can only offer insight into possible beliefs and values held by this section of society. A further limitation to emerge from the sample group was that all participants were involved with Playcentre New Zealand. Parents within this organisation are valued highly as children's first teachers and the underpinnings of parent education and involvement are central to its philosophy (Playcentre New Zealand, 2012b). Consequently, the study may not accurately represent the diversity of views and perceptions about the importance of play in the first three years held by all New Zealand parents.

As the focus topic of this thesis is considerably under-researched, future studies examining parental perceptions about the importance of play in promoting early development is deemed necessary in order to further develop understandings in this area of early childhood. However, based on the findings of this study, as well as the acknowledged limitations, three recommendations for future research have been formulated. First, it is suggested that future research utilises a sample group which better represents the diversity of the parent population in order to gauge a truer understanding of perceptions held by this demographic. It may also be valuable to survey early childhood educators in order to compare and understand the perceptions held by both parents and teachers, who are influential people in the lives of young children. Second, it is recommended that future research provides a deeper examination into the 
relationship between parental perception and the amount of screen time in which young children engage. Despite the debate around its appropriateness in early childhood, this area was not examined in-depth in this thesis due to the current study's focus on play. As a result, findings suggest some gaps in analysis which may have offered greater insight into children's early exposure to electronic media. For example, it may be valuable to examine correlations between structured and unstructured play perception and how appropriate parents deem television, DVD, and computer use for young children. An investigation into the rationales behind such parental perception is also suggested. This may offer deeper understanding into the knowledge parents hold about the relationship between unstructured play and the development of imaginative, creative, and later abstract thought rather than simply perceiving free play to be a lack of structured activity. The final recommendation for future research is to utilise the current survey with additional questions regarding the value of parental education into the role of play in child development and what forms of support parents with infants and toddlers would welcome. This recommendation could assist in the development of programmes aimed to support and educate parents whilst simultaneously advocating for best practice for the child. Follow-up studies utilising the current survey could provide insight into the effectiveness of such programmes in developing attitudes and values conducive to positively fostering the holistic development and wellbeing of young children.

\section{Theoretical and applied implications}

Two key findings from this study generate implications in regard to the role of the parent, early childhood education, parent education, and child development and wellbeing. The first is that the perceptions held by participants, in relation to the type of play they value, directly influences children's early experiences. Second, most parents from this study highly valued free and unstructured play for their infants and toddlers. These parents were generally well educated, both in terms of tertiary qualifications as well as being educated through the Playcentre philosophy. It could be argued that when parents are offered support and education around how unstructured play can promote holistic child development, more children could be offered greater opportunities to engage in natural and meaningful learning through play and the negative effects of the hurried child could be minimised. 


\section{The role of the parent}

As findings from this study suggest, the values, knowledge, experiences, and perceptions held by parents can greatly influence the early experiences and consequent learning of their children during the first three years of life. It is therefore paramount to consider these perceptions and recognise the crucial role parents play in promoting or hindering children's holistic development and wellbeing (Braun, 1992; Dancy, 2000; Roopnarine, et al., 2003). Research and literature has identified the significance of first attachments between primary caregiver and child in relation to brain development. When children are offered positive, responsive, and consistent relationships with key caregivers they are in the state required for neural connections to be made and consequent learning to occur (Brownlee, 2008; Fancourt, 2004; Rushton, et al., 2010; Shonkoff, 2007). Through this attachment a sense of security is fostered in children, enabling them to engage in, and learn from, meaningful play experiences (Atwool, 2002; Brown, 2010; Klein, 2002). The importance of this first relationship has also been linked to other specific types of learning. A study by Parker et al. (1999) found that parental ability to understand and facilitate play opportunities predicted positive outcomes for children including an increase in independence and creativity. As can be seen, the parent and child relationship appears to be the foundational base from which children can learn and develop through play.

This present study highlights some interesting qualitative findings in relation to the role of the parent within play experiences. While participants acknowledged the importance of child led unstructured play in promoting natural development, comments were made regarding the importance of certain adult involvement in free play which differs from the adult led focus of structured play. This included the need for the adult to set up the play environment along with the importance of parents being present and available to children in case guidance or support is required. Hewes (2006) acknowledges this by stating that free play is most beneficial to children when they are provided plenty of uninterrupted time to engage in a rich learning environment comprising a variety of open ended play objects. Ruebke (2009) further promotes the role of the adult by stating that in order to be effective, unstructured play requires that caregivers offer children the freedom to explore and make choices in a safe space. The art of observation has been acknowledged as an essential technique for caregivers to develop as it can offer valuable insight into the child's learning, interests, and current level of development (Hamilton \& 
McFarlane, 2005). With this knowledge, parents are better equipped to make insightful judgements about how and when to step in to offer children gentle guidance and support in a way which does not hinder the natural learning offered to children through the sacred pursuit of play (Gerber, 2002).

\section{Early childhood education}

Implications from this study also extend to early childhood education and teachers. Parents hold great responsibility and influence in regard to the choices they make for their children. As a consequence it appears necessary for educators to recognise and value the role of the parent and strive to develop professional partnerships whereby the best interests of the child are upheld (Braun, 1992). Nutbrown (1994) proffers six principles for educators to follow when developing such partnerships with parents. These are: recognising that parents are the primary carers and educators of their children; ensuring consistency, continuity, and progression are key elements when involving parents in the educational setting; offering equal opportunities to all parents; working in the interests of the children; fostering mutual respect; lovingly acknowledging the powerful roles that both parents and educators play in the lives of children. Once this partnership has been established, educators are in a position to be able to support parents. This can be achieved through sharing current research and understandings around child development to which parents may not otherwise have access.

With this comes the implication for early childhood educators to continue their own professional development around the importance of unstructured play in promoting development during the early years. Such education can enable teachers to expand their own understandings, keep informed about current research, better articulate this knowledge to caregivers, and evolve teaching practice (Almon, 2004). When educators recognise and understand the importance of unstructured play, they can strive to actively create environments and implement pedagogical practice conducive to promoting holistic development. This leads early childhood educators into a role of advocacy through promoting the development of policy and practice around a free play based pedagogical framework of care and education for young children. This would appear to be important due to the reported increase in pressure on both parents and teachers to prepare young children for success in the assessment based environment of primary school (Milteer \& Ginsburg, 2012). With this advocacy comes the hope that the effects of the hurried child 
phenomenon can be minimised and the holistic development of the child can be trusted to naturally unfold.

\section{Parent education}

It has been discussed above and in prior research that a key way to promote the positive early experiences of young children is through the provision of parental education around child development and the role of play in promoting holistic learning and growth (Milteer \& Ginsburg, 2012; Stipek, et al., 1992). This current study has identified that parents who are more highly educated support unstructured play more than those with a school qualification or less. This suggests that parent education is a key way in which the significance of unstructured play in the development of infants and toddlers can be promoted. The study by Stipek et al. (1992), which obtained similar findings, recommends that parents with lower qualification levels would benefit greatly from programmes which discuss the positive effects of unstructured and informal early learning through play. The value of such education is also evident from the findings in this study which examined the views held by Playcentre parents. The overall trend was that unstructured play was perceived to be important and, as a result, many children spent a large amount of their day involved in free play experiences. A key philosophy of this organisation is to empower parents in their role by offering parent education around early childhood, especially the role of play in promoting development and wellbeing (Playcentre New Zealand, 2012b). This study indicates that such education could expand the beliefs and understandings held by parents which, in turn, could greatly influence the child's early experiences.

However, it has been argued that there is a lack of such parental support available to caregivers, many of whom have little knowledge about optimal child rearing practices until they actually have children of their own (Dancy, 2000). As a result, an implication arises about the need for the development of accessible and informative parent education programmes. These should aim to educate parents about child development and the importance of the parent and child relationship acting as the base from which children can engage in meaningful and child driven play. With this, parents can be better encouraged to make conscious and informed decisions around their parenting choices and question the socially acceptable parenting trends of the time. 


\section{Child development and wellbeing}

According to Bronfenbrenner's ecological systems theory, child development is greatly influenced by the contextual elements surrounding the child, especially the element of relationships (as cited in Smith, 1998). As a result, the choices caregivers make can greatly impact on their children's learning and consequent wellbeing. The findings from this study confirm that parental perceptions influence the way in which children spend their time and how their development is promoted. Therefore, it is the responsibility of all those involved in the life of a child to understand how best to foster the naturally unfolding choreography of development to ensure the best start to life during the crucial and foundational first three years.

As this thesis has indicated, there is great debate within the field of early childhood as to what best practice means, especially in relation to play based learning. For example, the phenomenon of the hurried child suggests that modern infants, toddlers, and preschool children are experiencing far more structured play and deliberate teaching focused on cognitive skills rather than on holistic growth. However, there is a growing body of research and literature which questions the worth of this trend which is seeing the diminishing prevalence of free play (Elkind, 2007; Gleave, 2009; Gray, 2011; Nicolopoulou, 2010; Zigler \& Bishop-Josef, 2006). A significant proportion (i.e., $85 \%$ ) of the brain is believed to be fully developed by the time a child reaches the age of three years and, as a result, children's experiences during these initial years lay the foundation for future learning, happiness, and success (Fancourt, 2004; Perry \& Szalavitz, 2006). Meaningful and child led play has been identified as a key component of this healthy brain development while too much direction or structure can negatively effect the hardwiring of neurons (Frost, et al., 2008). Canning (2007) argues that free play enables children to be active participants in the learning process which can lead to the development of internally motivated and self directed learners in later life. Resourcefulness, resilience, social competence, empathy, and cognition, such as creative and abstract thought, are also believed to be fostered by the early experiences offered through unstructured play (Gimtrova \& Gimtrov, 2003; Hamilton \& McFarlane, 2005; Jenkinson, 2001). These areas of development are arguably essential traits to possess in order to live a productive, whole, and meaningful life.

When children are offered time and opportunity to be active participants in the play process and follow their internal agendas, holistic development and wellbeing can be nurtured and learning can be more strongly consolidated (Canning, 2007; Jenkinson, 2001; Zigler \& 
Bishop-Josef, 2006). With this comes the responsibility for caregivers to provide a safe and rich learning environment for children and minimise their structured activities so they can become fully engaged in their chosen play experiences (Gleave, 2009; Hewes, 2006; Ruebke, 2009). It also requires that parents trust in their child's natural development, rather than rush or extend it through the use of structured activities and programmes aimed to teach specific skills (Brownlee, 2008; Dancy, 2000; Gerber, 2002). From here, children can be nurtured to become authentic individuals who feel valued and respected, who can transition through life's challenges and changes, who can develop the new thought and idea, who feel secure in the knowledge of who they are, and who can recognise their special place within this world.

\section{Conclusion}

Every child has the right to play (Child Rights Information Network, 2012). It is an innate and universal disposition central to healthy development and holistic wellbeing (Almon, 2004; Brown, 2010; Frost, et al., 2008; Pearce, 1992). However, it is the type of play that best supports children under the age of three years which is the subject of recent debate (Elkind, 2007; Gleave, 2009; Gray, 2011; Nicolopoulou, 2010). The two types of play examined in this study were structured play and unstructured or free play. A predetermining factor in the type of play that a child is involved in has been identified as the perceptions held by parents about the importance of both play types. The examination of parental perceptions in this thesis found that these beliefs influence the choices parents make about the way in which children spend their time. It is because of the central role parents have in the lives of their children that their beliefs and knowledge need to be recognised and understood in order to offer valuable insights into children's early experiences and consequent learning (Dancy, 2000; Roopnarine, et al., 2003).

This study found that the majority of parents valued unstructured play more highly than structured play. However, participants were educated in their parenting roles through Playcentre, suggesting that parental education can empower parents to make informed and conscious decisions around child rearing practices. The availability of such education, based upon trusting in the child's innate developmental potential, may therefore contribute to a greater parental understanding about the value of unstructured play in holistically supporting children. This, in turn, could minimise the reported negative impacts of the hurried child phenomenon. 


\section{Reference List}

Almon, J. (2004). The vital role of play in childhood. Chestnut Ridge, NY: Waldorf Early Childhood Association of North America.

American Academy of Pediatrics. (2011). Media use by children younger than 2 years. Pediatrics: Official Journal of the American Academy of Pediatrics, 128(5), 1040-1045.

Atwool, N. (2002). Attachment and the developing child. Childrenz Issues, 6(2), 21-43.

Bergen, D. (2002). The role of pretend play in children's cognitive development. Early Childhood Research and Practice, 4(1), 1-8.

Berk, L. E. (1994). Vygotsky's theory: The importance of make-believe play. Young Children, 50(1), 30-39.

Bertram, T., \& Pascal, C. (2002). Early years education: An international perspective. London, England: Qualifications and Curriculum Authority.

Bradley, R. H. (1985). Social-cognitive development and toys. Topics in Early Childhood Special Education, 5(3), 11-29.

Braun, D. (1992). Working with parents. In G. Pugh (Ed.), Contemporary Issues in Early Education (pp. 175-190). London, England: Paul Chapman Publishing.

Bredekamp, S., \& Rosegrant, T. (1992). Reaching potentials: Appropriate curriculum and assessment for young children. Washington: National Association for the Education of Young Children.

Brown, S. (2010). Play: How it shapes the brain, opens the imagination and invigorates the soul. Melbourne, Australia: Scribe Publications.

Brownlee, P. (2008). Dance with me in the heart: The adults' guide to great infant-parent partnerships. Waitakere, New Zealand: New Zealand Playcentre Federation.

Burdette, H. L., \& Whitaker, R. C. (2005). Resurrecting free play in young children. Archives of Pediatrics and Adolescent Medicine, 159(4), 46-50.

Canning, N. (2007). Children's empowerment in play. European Early Childhood Education Research Journal, 15(2), 227-236.

Child Rights Information Network. (2012). Convention on the rights of the child. Retrieved from http://www.crin.org/docs/resources/treaties/uncrc.asp 
Christakis, D. A., Zimmermann, F. J., DiGiuseppe, D. L., \& McCarty, C. A. (2004). Early television exposure and subsequent attentional problems in children. Pediatrics: Official Journal of the American Academy of Pediatrics, 113(4), 708-713.

Dancy, R. B. (2000). You are your child's first teacher: What parents can do with and for their children from birth to age six. Berkeley, CA: Celestial Arts.

Edwards, C. P., Sheridan, S. M., \& Knoche, L. L. (2008). Parent engagement and school readiness: Parent-child relationships in early learning. Lincoln, NE: Nebraska Center for Research on Children, Youth, Families and Schools.

Elkind, D. (2007). The power of play: Learning what comes naturally. Philadelphia, PA: Da Capo Press Lifelong Books.

Fancourt, R. (2004). The first three years last forever. Retrieved from http://www.brainwave.org.nz/about/the-first-three-years-last-forever/

Farne, R. (2005). Pedagogy of play. Topoi, 24(2), 169-181.

Field, A. (2009). Discovering statistics using SPSS. (3rd ed.). Thousand Oaks, LA: Sage Publication.

Fisher, K. R., Hirsh-Pasek, K., Golinkoff, R. M., \& Gryfe, S. G. (2008). Conceptual split? Parents' and experts' perceptions of play in the 21st century. Journal of Applied Developmental Psychology, 29(4), 305-316.

Fleer, M. (2011). Kindergarten in cognitive times: Imagination as a dialect relation between play and learning. International Journal of Early Childhood., 43(3), 245-259.

Frost, J. L. (2009). Back to nature and the emerging child saving movement: Restoring children's outdoor play. Children and Nature Network Writing Series, 1(3), 1-13.

Frost, J. L., Wortham, S. C., \& Reifel, S. (2008). Play and child development (3rd ed.). Upper Saddle River, NJ: Pearson Education, Inc.

Gerber, M. (2002). Dear parent: Caring for infants with respect (2nd ed.). Los Angeles, CA: Resources for Infant Educarers.

Gimtrova, V., \& Gimtrov, J. (2003). The impact of teacher-directed and child-directed pretend play on cognitive competence in kindergarten children. Early Childhood Education Journal, 30(4), 241-246.

Gleave, J. (2009). Children's time to play: A literature review. London, England: Play England. 
Gray, P. (2011). The decline of play and the rise of psychopathology in children and adolescents. American Journal of Play, 3(4), 443-463.

Haight, W. L., Parke, R. D., \& Black, J. E. (1997). Mothers' and fathers' beliefs about and spontaneous participation in their toddlers' pretend play. Merrill-Palmer Quarterly, 43(2), 271-290.

Hamilton, N., \& McFarlane, J. (2005). Children learn through play. Putting Children First, 22(14), 10-11.

Healy, J. M. (1991). Endangered minds: Why children can't think and what we can do about it. New York, NY: Simon and Schuster.

Hewes, J. (2006). Let the children play: Nature's answer to early learning. Montreal, Canada: Early Childhood Learning Knowledge Centre.

Hirsh-Pasek, K., \& Glolinkoff, R. M. (2003). Einstein never used flash cards. Ontario, Canada: Rodale Books.

Hughes, F. P. (2003). Spontaneous play in the 21 st century. In O. N. Saracho \& B. Spodek (Eds.), Contemporary perpsectives on play in early childhood education. Greenwich, CT: Information Age Publishing.

Izumi-Taylor, S., Samuelsson, I. P., \& Rogers, C. S. (2010). Perspectives of play in three nations: A comparative study in Japan, the United States and Sweden. Early Childhood Research and Practice, 12(1).

Jenkinson, S. (2001). The genius of play: Celebrating the spirit of childhood. Gloucestershire, England: Hawthron Press.

Jensen, A. F. (2002). Time for playful learning? A cross-cultural study of parental values and attitudes towards children's time for play. Billund, Denmark: Lego Learning Institute.

Johnson, B., \& Christensen, L. (2008). Educational research: Quantitative, qualitative and mixed approaches (3rd ed.). Los Angeles, CA: Sage Publications.

Jordon, A. B., Hersey, J. C., McDivitt, J. A., \& Heitzler, C. D. (2006). Reducing children's television viewing time: A qualitative study of parents and their children. Pediatrics: Official Journal of the American Academy of Pediatrics, 118(5), 1303-1310.

Katz, L. G. (2008). Play and learning in early chldhood settings: International perspectives. International Journal of Early Childhood, 40(2), 147-149. 
Klein, A. G. S. (2002). Infant and toddler care that recognizes competence: Practices at the Pikler Institute. Dimensions of Early Childhood, Spring, 11-17.

Lester, S., \& Russell, W. (2010). Children's right to play: An examination of the importance of play in the lives of children worldwide. The Hague, Netherlands: Bernard van Leer Foundation.

Louv, R. (2005). Last child in the woods: Saving our children from nature-deficit disorder. London, England: Atlantic Books.

Marcon, R. A. (2002). Moving up the grades: Relationship between preschool model and later school success. Early Childhood Research and Practice, 4(1), 1-31.

Maxwell, K., \& Clifford, R. M. (2004). School readiness assessment. Young Children, 59(1), 4246.

May, H. (2001). Politics in the playground: The world of early childhood in postwar New Zealand. Wellington, New Zealand: Bridget Williams Books.

May, H. (2004). The discovery of early childhood. Auckland, New Zealand: Auckland Univeristy Press.

Milteer, R. M., \& Ginsburg, K. R. (2012). The importance of play in promoting healthy child development and maintaining strong parent-child bond: Focus on children in poverty. Pediatrics: Official Journal of the American Academy of Pediatrics, 129(1), 204-213.

Morse, J., \& Field, P. (1995). Qualitative Research Methods for Health Professionals (2nd ed.). London, England: Sage Publications.

Murata, N. M., \& Maeda, J. K. (2002). Structured play for preschoolers with developmental delays. Early Childhood Education Journal, 29(4), 237-240.

New Zealand Ministry of Education. (1996). Te Whariki: Early childhood curriculum. Wellington: Learning Media.

Nicolopoulou, A. (2010). The alarming disappearance of play from early childhood education. Human Development, 53(1), 1-4.

Nutbrown, C. (1994). Threads of thinking. London: Paul Chapman Publishing.

Oldfield, L. (2001). Free to learn: Introducing Steiner Waldorf early childhood education. Gloucestershire, England: Hawthorn Press.

Pallant, J. (2007). SPSS survival manual. Buckingham, England: Open University Press. 
Parker, F. L., Boak, A. Y., Griffin, K. W., Ripple, C., \& Peay, L. (1999). Parent-child relationship, home learning environment and school readiness. School Psychology Review, 28(3), 413-425.

Pearce, J. C. (1992). Magical child. London, England: Penguin Books.

Pelletier, J., \& Brent, J. M. (2002). Parent participation in children's school readiness: The effects of parent self-efficacy, cultural diversity and teacher strategies. International Journal of Early Childhood, 34(1), 45-60.

Perry, B. D., \& Szalavitz, M. (2006). The boy who was raised as a dog. New York, NY: Basic Books.

Playcentre New Zealand. (2012a). Playcentre: About Playcentre. Retrieved from http://www.playcentre.org.nz/about_us.php

Playcentre New Zealand. (2012b). Playcentre: Philosophy. Retrieved from http://www.playcentre.org.nz/philosophy.php

Pulanski, M. (1970). Play as a function of toy structure and fantasy disposition. Child Development, 41(2), 531-537.

Raichle, B. (2008). Creating a home for body, soul and spirit: A new approach to childcare. Spring Valley, NY: Waldorf Early Childhood Association on North America.

Ranz-Smith, D. J. (2007). Teacher perception of play: In leaving no child behind are teachers leaving childhood behind? Early Education and Development, 18(2), 271-303.

Rivkin, M. S. (1995). The great outdoors: Restoring children's right to play outside. Washington, DC: National Association for the Education of Young Children.

Roopnarine, J. L., Shin, M., Jung, K., \& Hossain, Z. (2003). Play and early development and education: The instantiation of parental belief systems. In O. N. Saracho \& B. Spodek (Eds.), Contemporary Perspectives on Play in Early Childhood Education (pp. 115-130). Greenwich, CT: Information Age Publishing.

Rothlein, L., \& Brett, A. (1987). Children's, teachers' and parents' perceptions of play. Early Childhood Research Quarterly, 2(1), 45-53.

Rubin, K. H. (1985). Toys and play behaviours: an overview. Topics in Early Childhood Special Education, 5(3), 1-9.

Ruebke, P. (2009). More time and space for free play in early childhood care. Strasbourg, France: European Early Childhood Education Research Association. 
Rushton, S., Juola-Rushton, A., \& Larkin, E. (2010). Neuroscience, play and early childhood education: Connections, implications and assessment. Early Childhood Education Journal, 37(5), 351-361.

Sandberg, A., \& Samuelsson, I. P. (2005). An international study of gender differences in preschool teachers' attitudes towards children's play. Early Childhood Education Journal, 32(5), 297-305.

Shin, N. (2004). Exposing pathways from television viewing to academic achievment in school age children. The Journal of Genetic Psychology, 165(4), 367-381.

Shonkoff, J. P. (2007). The timing and quality of early experiences combine to shape brain architecture: Working Paper No. 5. Cambridge, MA: Center on the Developing Child Harvard University.

Singer, D. G., Singer, J. L., D'Agostino, H., \& DeLong, R. (2009). Children's pastimes and play in sixteen nations: Is free play declining. American Jounral of Play, 1(3), 283-312.

Siraj-Blatchford, I., Sylva, K., Muttock, S., Gilden, R., \& Bell, D. (2002). Researching effective pedagogy in the early years. London, England: Queen's Printer.

Smith, A. (1998). Understanding children's development (4th ed.). Wellington, New Zealand: Bridget Williams Books.

Spodek, B., \& Saracho, O. N. (2003). Early childhood educational play. In O. N. Saracho \& B. Spodek (Eds.), Contemporary Perspectives on Play in Early Childhood Education (pp. 171-179). Greenwich, CT: Information Age Publishing.

Statistics New Zealand. (2010). New Zealand childcare survey. Retrieved from Www.stats.govt.nz

Statistics New Zealand. (2012). Births and deaths. Retrieved from http://www.stats.govt.nz/browse_for_stats/population/births.aspx

Stephenson, A. M. (1999). Opening the outdoors: A case study of young children's outdoor experiences in one childcare centre. Wellington, New Zealand: Institute for Early Childhood Studies Victoria University of Wellington.

Stipek, D., Milburn, S., Clements, D., \& Daniels, D. H. (1992). Parents' beliefs about appropriate education for young children. Journal of Applied Developmental Psychology, 13(3), 293310. 
Tandon, P. S., Zhou, C., \& Christakis, D. A. (2012). Frequency of parent-supervised outdoor play of US preschool-aged children. Archives of Pediatrics and Adolescent Medicine, 16.

Webster-Stratton, C., \& Reid, M. J. (2004). Strengthening social and emotional competence in young children - the foundation for early school readiness and success: Incredible years classroom social skills and problem-solving curriculum. Infants and Young Children, 17(2), 96-113.

White, J., \& Rockel, J. (2008). The rights and rites of play for toddlers in Aotearoa New Zealand. The First Years: Nga Tau Tuatahi. New Zealand Journal of Infant and Toddler Education, 10(1), 25-31.

Zeece, P. D., \& Graul, S. K. (1990). Learning to play: Playing to learn. Daycare and Early Childhood, 18(1), 1-13.

Zigler, E. F., \& Bishop-Josef, S. J. (2006). Play = learning: How play motivates and enhances children's cognitive and social-emotional growth. New York, NY: Oxford University Press.

Zimmermann, F. J., Christakis, D. A., \& Meltzoff, A. N. (2007). Television and DVD/video viewing in children younger than 2 years. Archives of Pediatrics and Adolescent Medicine, 161(5), 473-479. 


\section{Appendices}

\section{Appendix A: Play Survey}

Kia ora and thank you for choosing to participate in this survey on play. It has been designed for parents with a child younger than three years of age who does not attend full-time childcare. If this is you please read the information below before commencing this survey by clicking the consent button below.

\section{Purpose of the Study}

I am a Masters of Education student in the School of Educational Psychology and Pedagogy at Victoria University of Wellington, conducting research under the supervision of Associate Professor Vanessa Green. You are invited to participate in a research study on parental perceptions on play and how young children spend their time. The purpose of this study is to gain knowledge around parental views of the role of play during early childhood. The survey will take approximately 5 minutes of your time to complete and contains basic questions about you and your child, how your child spends their time, and your perceptions towards structured play, unstructured play, and child development.

\section{Participation and Withdrawal}

Your decision to participate is completely voluntary and you have the right to withdraw your participation from this study at any time before the survey is submitted. You may skip any questions you do not wish to answer and if you do not want to continue just close your browser.

\section{Confidentiality, Data Storage, and Deletion}

Your participation in this research will be completely anonymous and data will be reported as a whole, representing averages or generalisations about the responses. Once the survey has been closed the information provided will be downloaded onto computers belonging to the researcher of this study. These files will not be identifiable in anyway. Only the researcher and her supervisor will have access to individual survey data. The data will be stored for 5 years after publication and then destroyed. We will request that Qualtrics destroy the data on their system once the information required has been retrieved.

\section{Ethics}

The research has been assessed and approved by Victoria University Faculty of Education Ethics Committee. If at any time you have questions or concerns about your treatment as a research 
participant in this study please contact Dr Allison Kirkman (allison.kirkman@vuw.ac.nz) who is the current Chair of the Victoria University of Wellington Human Ethics Committee.

\section{Reporting/Dissemination}

The results from this study may be presented in educational settings, at professional conferences

and may be published in professional journals. If you are interested in reading the final report, a copy will be available online next year through the Faculty of Education, Victoria University of Wellington website.

\section{Questions}

If you have questions or concerns regarding your participation please contact:

Masters Student Suzanne Holland

School of Educational Psychology and Pedagogy

Faculty of Education, Victoria University of Wellington

suzanne.holland@vuw.ac.nz

Associate Professor Vanessa Green, Ph.D.

School of Educational Psychology and Pedagogy

Faculty of Education, Victoria University of Wellington

vanessa.green@vuw.ac.nz

$\square$ Consent: I have read the above information and understand what is being requested of me as a participant in this study. I freely consent to participate in this anonymous online survey and certify that $I$ am at least 18 years of age.

Q1: What is your gender?

Male

Female

\section{Q2: What is your age group?}

Under 20

20-29

30-39

40-49

50 and over 
Q3: What ethnic group do you identify with?

New Zealand European

Maori

European

Pacific Islander

Asian

Other (please specify)

Q4: What is your highest academic qualification?

Left school without formal qualifications

Completed NCEA Level 1 or equivalent (e.g. completed $5^{\text {th }}$ form and passed School certificate exams)

Completed NCEA Level 2 or equivalent (e.g. completed $6^{\text {th }}$ form and gained University

Entrance)

Completed NCEA Level 3 or equivalent (e.g. completed $7^{\text {th }}$ form and passed Bursary exams)

Certificate (Please specify)

Diploma (Please specify)

Bachelor Degree (Please specify)

Other (Please specify)

Q5: How many children do you have?

One

Two

Three

Four

Five or more

Please answer the remainder of the questions in relation to one of your children under the age of three years who does not attend full-time childcare.

Q6: What is your child's gender?

Male

Female 
Q7: What is your child's age?

0-6 months

7-12 months

13-18 months

19-24 months

25-30 months

31-35 months

Please note the following definitions before you continue.

Structured play refers to experiences which are adult led with set rules or outcomes and does not include routine times such as feeding or toileting.

Unstructured play refers to experiences which are child led with no set rules or outcomes and does not include screen time.

Q8: In an average DAY how many hours does your child spend involved in structured play?

0

1

2

3

4

5

6 or more

Q9: In an average DAY how many hours does your child spend involved in unstructured play?

0

1

2

3

4

5

6 or more 
Q10: In an average DAY how many hours does your child spend involved in screen time (e.g. television, DVDs, and computer use)?

0

1

2

3

4

5

6 or more

Q11: In an average WEEK which of the following activities does your child attend?

Music class

Gym class

Swimming lesson

Playgroup

Playcentre

Parent-child education class

Part-time childcare (e.g. crèche, kindergarten, nanny care)

Other (Please specify)

None of the above 


\section{Q12: Please select the answer which best represents how you feel about each statement}

Play Perception Scale

\begin{tabular}{|c|c|c|c|c|c|}
\hline & $\begin{array}{l}\text { Strongly } \\
\text { Disagree }\end{array}$ & Disagree & $\begin{array}{l}\text { Neither } \\
\text { agree or } \\
\text { disagree }\end{array}$ & Agree & $\begin{array}{c}\text { Strongly } \\
\text { Agree }\end{array}$ \\
\hline $\begin{array}{l}\text { Unstructured playing time is also learning time for } \\
\text { child. }\end{array}$ & 1 & 2 & 3 & 4 & 5 \\
\hline $\begin{array}{l}\text { Children aged } 0 \text {-three years require structured } \\
\text { ivities to support development. }\end{array}$ & 1 & 2 & 3 & 4 & 5 \\
\hline $\begin{array}{l}\text { Children aged 0-three years require deliberate early } \\
\text { hing to enable them to be school ready. }\end{array}$ & 1 & 2 & 3 & 4 & 5 \\
\hline $\begin{array}{l}\text { Toys which have many uses better support child } \\
\text { elopment than toys which can only be used in one } \\
\text { cific way. }\end{array}$ & 1 & 2 & 3 & 4 & 5 \\
\hline $\begin{array}{l}\text { It is important for my child to have unstructured } \\
\text { eutdoors. }\end{array}$ & 1 & 2 & 3 & 4 & 5 \\
\hline $\begin{array}{l}\text { Screen time (e.g. television, DVDs, and computer } \\
\text { is appropriate for my child. }\end{array}$ & 1 & 2 & 3 & 4 & 5 \\
\hline $\begin{array}{l}\text { It is important for my child to have time to self } \\
\text { ct their play. }\end{array}$ & 1 & 2 & 3 & 4 & 5 \\
\hline $\begin{array}{l}\text { Structured play is more valuable to my child's } \\
\text { elopment than unstructured play. }\end{array}$ & 1 & 2 & 3 & 4 & 5 \\
\hline
\end{tabular}

Q13: Please make any further comments on the importance of structured and unstructured play during the first three years of childhood. 


\section{Appendix B: Ethics committee letter}

3 April 2012

Suzanne Holland

MEd student

Victoria University of Wellington Faculty of Education

$\mathrm{C} /$ - School of Educational Psychology and Pedagogy

Donald Street

Wellington

\section{Dear Suzanne}

\section{RE: Ethics application SEPP/2012/06 RM 19208}

I am pleased to advise you that your ethics application 'Parental perceptions about the importance of free play in the first three years', with the required changes, has been approved by the Victoria University of Wellington Faculty of Education Ethics Committee. Please note that the approval for your research to commence is from the date of this letter.

Best wishes for your research.

Yours Sincerely

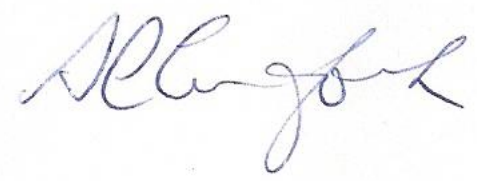

Dr Sue Cornforth

Co-Convener

Victoria University of Wellington Faculty of Education Ethics Committee 